Article

\title{
What Do Global Climate Models Tell Us about Future Arctic Sea Ice Coverage Changes?
}

\author{
Ge Peng ${ }^{1, *(\mathbb{C}}$, Jessica L. Matthews ${ }^{1}\left(\mathbb{D}\right.$, Muyin Wang ${ }^{2,3}$, Russell Vose ${ }^{4}$ and Liqiang Sun ${ }^{1}$ \\ 1 North Carolina Institute for Climate Studies, North Carolina State University, Asheville, NC 28801, USA; \\ jlmatthe@ncsu.edu (J.L.M.); lsun4@ncsu.edu (L.S.) \\ 2 NOAA Pacific Marine Environmental Laboratory, Seattle, WA 98115, USA; muyin.wang@noaa.gov \\ 3 University of Washington, Seattle, WA 98115, USA \\ 4 NOAA National Centers for Environmental Information, Asheville, NC 28801, USA; russell.vose@noaa.gov \\ * Correspondence: gpeng@ncsu.edu
}

Received: 12 December 2019; Accepted: 16 January 2020; Published: 17 January 2020

check for updates

\begin{abstract}
The prospect of an ice-free Arctic in our near future due to the rapid and accelerated Arctic sea ice decline has brought about the urgent need for reliable projections of the first ice-free Arctic summer year (FIASY). Together with up-to-date observations and characterizations of Arctic ice state, they are essential to business strategic planning, climate adaptation, and risk mitigation. In this study, the monthly Arctic sea ice extents from 12 global climate models are utilized to obtain projected FIASYs and their dependency on different emission scenarios, as well as to examine the nature of the ice retreat projections. The average value of model-projected FIASYs is 2054/2042, with a spread of 74/42 years for the medium/high emission scenarios, respectively. The earliest FIASY is projected to occur in year 2023, which may not be realistic, for both scenarios. The sensitivity of individual climate models to scenarios in projecting FIASYs is very model-dependent. The nature of model-projected Arctic sea ice coverage changes is shown to be primarily linear. FIASY values predicted by six commonly used statistical models that were curve-fitted with the first 30 years of climate projections (2006-2035), on other hand, show a preferred range of 2030-2040, with a distinct peak at 2034 for both scenarios, which is more comparable with those from previous studies.
\end{abstract}

Keywords: arctic; first ice-free Arctic summer year; climate models; Climate Data Record; sea ice extent; Coupled Model Intercomparison Project

\section{Introduction}

Rapid and accelerated Arctic sea ice loss has brought the possibility of a nearly ice-free Arctic summer well into our near future (e.g., [1-4]). An Arctic ice-free state is defined as when the total Arctic sea ice extent (SIE) falls below one million square kilometers $\left(10^{6} \mathrm{~km}^{2}\right)$ [1]. The rapid changes in sea ice pose challenges to the Arctic ecosystem, including the decline of habitat for Arctic animals such as polar bears and increases in coastal erosion that may directly impact Arctic people [5-7]. It also provides opportunities, such as the opening up of shipping routes. Therefore, an accurate projection of the first ice-free Arctic summer year (FIASY) would be beneficial to business strategic planning, climate adaptation and risk mitigation, and national security.

By using sea ice extent predictions from six statistical models that were curve-fitted with satellite observational data from 1979-2015, Peng et al. [4] demonstrated that the predicted FIASYs are converging around the year 2037, with a margin of error of seven years and with the earliest FIASY predicted to be in 2031. A similar conclusion was obtained by Wang and Overland [1,2], who used a subset of coupled climate models that participated in the Coupled Model Intercomparison Project (CMIP) Phase 3 and Phase 5 (CMIP3 and CMIP5, respectively). 
Projections of sea ice extent from climate models offer a dynamically consistent alternative to observations for examining the FIASY. Climate models provide both simulations and projections of ice state. The CMIP5 Arctic sea ice retreat trends have been shown to be more consistent over the satellite period compared to that of CMIP3, but these simulated trends are nonetheless smaller than the observed trends $[3,8]$.

By using 56 ensemble members from 20 CMIP5 climate models, Stroeve et al. [3] showed that about a third of these 56 ensemble members projected nearly ice-free Arctic conditions by the end of this century for a midrange emission scenario, i.e., the Representative Concentration Pathway 4.5 (RCP4.5) with the earliest FIASY at 2020 with a large uncertainty.

Based on six CMIP3 models, Wang and Overland [1] showed that the FIASYs could be reached by 2037 on average, with the earliest FIASY occurring in year 2028 under both the medium and high emission scenarios. The CMIP5 FIASYs are fairly close to those projected by CMIP3 - with a median value of 2035 and spanning 2021-2043 under the RCP8.5 emission scenario [2]. Given the fact that the latest annual Arctic sea ice minimum was at $4.15\left(10^{6} \mathrm{~km}^{2}\right)$ on 18 September 2019 [9], it is unlikely that the Arctic summer will be nearly ice free (i.e., SIE is less than one million square kilometers) by the early 2020s.

Among the 35 CMIP5 climate models assessed, only 12 models simulated the distinct and realistic seasonal cycles of sea ice coverage when compared with observations [10]. In this paper, the performance of these 12 models in terms of simulating and projecting monthly Arctic sea ice extents is further evaluated by using a long-term, consistent satellite-based sea ice time series. A sensitivity analysis is then carried out by utilizing the same approach as in [4] but by using sea ice projections from the 12 CMIP5 models instead of the observed ice data. The goal in using only these 12 climate models that have simulated Arctic sea ice extent reasonably well is to reduce the uncertainty in projected future Arctic sea ice changes and therefore improve the quality of our analysis. The goals of this analysis are to examine the sensitivity of the projected FIASY values to different models and emission scenarios and to explore the nature of projected Arctic sea ice coverage changes as a function of different time periods and emission scenarios. The questions to be explored include: Would the FIASY values projected by these 12 global climate models be different from the previous studies? Are the projected rates of decline of Arctic sea ice extent minimum following a linear regression or are they more quadratic in nature for a given period and emission scenario? Are the results sensitive to time periods, scenarios, and models?

\section{Datasets}

\subsection{Climate Model Sea Ice Data}

The CMIP5 experiments included in this paper are historical simulations, climate projection runs for a midrange emissions scenario (RCP4.5), and climate projection runs for a high emissions scenario (RCP8.5) (see [11] for a summary of CMIP5 experiment design). These different types of experiments are hereinafter referred to as hist, $\mathrm{r} 45$, and $\mathrm{r} 85$, respectively.

Monthly time series of Arctic sea ice extents from one ensemble member each for 12 global climate models (see Table 1) were utilized in this analysis. These 12 out of 35 CMIP5 global climate models were identified by [10]. The selection criteria required that the model-simulated monthly sea ice extent and seasonal cycle magnitudes were within $20 \%$ of error of the observed values $[2,10]$. By using only these 12 climate models that simulated Arctic sea ice extent reasonably well, we aimed to reduce the uncertainty in projected future Arctic sea ice changes and therefore improve the quality of our analysis. 
The number of ensembles for each CMIP5 model varied. To give equal weight in our sensitivity analysis to each model, only sea ice data from one ensemble member were used in the analysis. The potential impact of different ensemble members is discussed in Section 4.

As shown in Table 1, the physical sea ice processes are represented in the 12 global climate models. Physical processes acting on sea ice are commonly divided into two categories: thermodynamic processes, which involve the transfer of heat or radiation, and dynamic processes, which move and deform the ice. Many of these processes are represented in climate models with parameterizations. Simplified mathematical representations are designed to capture their major features while working within the technical constraints of the models. For example, the Community Ice CodE (CICE), also known as the Los Alamos Sea Ice Model, is designed to couple with the ocean and atmosphere components of climate models and simulates thermodynamic and dynamic properties of Earth systems, including the growth, melt, and movement of sea ice [12]. CICE, or its variant, has been integrated into half of the 12 climate models (Table 1). Further details on the sea-ice representation can be found in the references listed in Table 1. 
Table 1. A list of models and their attributes (adapted from [10]).

\begin{tabular}{|c|c|c|c|c|c|}
\hline Model ID & Models Short Name & Country & Institute ID* & Sea Ice Model & Modeling Center/Group [Reference] \\
\hline M1 & ACCESS10 & Australia & CSIRO-BOM & CICE, v4.1 & \multirow{2}{*}{$\begin{array}{l}\text { Commonwealth Scientific and Industrial Research Organization (CSIRO) and the Bureau of Meteorology } \\
\text { (BOM) }[13,14]\end{array}$} \\
\hline M2 & ACCESS13 & Australia & CSIRO-BOM & CICE, v4.1 & \\
\hline M3 & CCSM4 & USA & NCAR & CICE, v4 & \multirow{2}{*}{$\begin{array}{l}\text { National Center for Atmospheric Research (NCAR) [15] } \\
\text { Community Earth System Model Contributors [16] }\end{array}$} \\
\hline M4 & CESM1-CAM5 & USA & NSF-DOE-NCAR & CICE, v4 & \\
\hline M5 & EC-EARTH & European Center & EC-EARTH & LM2 & EC-EARTH consortium [17] \\
\hline M6 & HadGEM2-AO & S. Korea & NIMR/KMA & $\begin{array}{l}\text { Sea ice component of } \\
\text { HadGOM2 }\end{array}$ & National Institute of Meteorological Research/Korea Meteorological Administration [18] \\
\hline M7 & HadGEM2-CC & UK & $\mathrm{MOHC}$ & Inspired from CICE & \multirow{2}{*}{$\begin{array}{l}\text { Met Office Hadley Centre (additional HadGEM2-ES realizations contributed by Instituto Nacional de } \\
\text { Pesquisas Espaciais) [18] }\end{array}$} \\
\hline M8 & HadGEM2-ES & UK & MOHC & Inspired from CICE & \\
\hline M9 & MIROC-ESM & Japan & MIROC & $\mathrm{COCO} v 3.4$ & \multirow{2}{*}{$\begin{array}{l}\text { Japan Agency for Marine-Earth Science and Technology (JAMEST), Atmosphere and Ocean Research } \\
\text { Institute (AORI) of the University of Tokyo, and National Institute for Environmental Studies (NIES) [19] }\end{array}$} \\
\hline M10 & MIROC-ESM-CHEM & Japan & MIROC & COCO v3.4 & \\
\hline M11 & MPI-ESM-LR & Germany & MPI-M & $\begin{array}{l}\text { Sea ice component of } \\
\text { MPI-OM }\end{array}$ & \multirow[t]{2}{*}{ Max Planck Institute for Meteorology [20] } \\
\hline M12 & MPI-ESM-MR & Germany & MPI-M & $\begin{array}{l}\text { Sea ice component of } \\
\text { MPI-OM }\end{array}$ & \\
\hline
\end{tabular}

* The Institute IDs and Modeling Center/Group are from: http://cmip5.whoi.edu/?page_id=339. 


\subsection{Observed Sea Ice Data}

Monthly sea ice concentration fields from a climate data record (CDR) produced by the National Oceanic and Atmospheric Administration (NOAA) and the National Snow and Ice Data Center (NSIDC), were utilized to derive the monthly sea ice extent time series. The CDR is a long-term, consistent, satellite-based, passive microwave record of sea ice concentration [21]. The CDR product leverages two well-established concentration algorithms developed by the Goddard Space Flight Center (GSFC) of the National Aeronautics and Space Administration (NASA) [21]: the NASA Team (NT; [22]) and Bootstrap (BT; [23]). A description and a verification of the dataset can be found in [24,25], respectively. The data files used in this study were from the latest version, v03r01 [21]. To utilize all the possible satellite data records, we used the Goddard merged concentration fields in the version v03r01 CDR data files.

\subsection{The Study Area and Analysis Methods}

The study area is north of 40-degree latitude. The Arctic SIE is defined as the area within the $15 \%$ sea ice concentration contour. The monthly Arctic SIE series were computed by using the monthly Arctic sea ice concentration fields of climate model output (historical simulations and projections) and satellite observations, respectively.

The projected first ice-free Arctic summer year, i.e., FIASY, is defined as the first year when the climate-model-projected SIE value falls below the threshold of one million square kilometers. The sensitivity of FIASY to the climate models and emission scenarios is examined in Section 3.4.

The nature and sensitivity of projected Arctic sea ice changes to models and different time periods and emission scenarios is examined in Section 3.5 by using predicted FIASY values from six commonly-used statistical models that are curve-fitted with the climate model ice data. These six statistical models are exponential (exp), Gompertz (gomp), logarithm (log), quadratic (quad), linear (lin), and linear with lag (linlag) and are defined as:

Exponential:

$$
y(t)=\alpha_{1}+e^{\alpha_{2} t}
$$

Gompertz:

$$
y(t)=\alpha_{1} e^{-e^{\frac{t-\alpha_{2}}{\alpha_{3}}}}
$$

Log:

$$
y(t)=\alpha_{1}+\alpha_{2} \ln \left(\alpha_{3}-t\right)
$$

Quadratic:

$$
y(t)=\alpha_{1}+\alpha_{2} t+\alpha_{3} t^{2}
$$

Linear:

$$
y(t)=\alpha_{1}+\alpha_{2} t
$$

Linear with lag:

$$
y(t)=\alpha_{1}+\alpha_{2} t+\alpha_{3} e^{-\left(\frac{t-\alpha_{4}}{\alpha_{5}}\right)}
$$

where model parameters, $\alpha_{i}, i=1, \ldots, 5$ were optimized by minimizing the sum of squared errors between the statistical model and input data via a simplex-based search approach (see [4] for additional information).

\section{Results}

\subsection{Temporal Characteristics of Model Historical Simulations and Projections}

The temporal distributions of Arctic SIEs from historical simulations (hist) and projections (for $\mathrm{r} 45$ and r85) from all 12 models are shown in Figures 1-3, respectively, while the time series of March and 
September Arctic SIEs, which usually represent the annual maximum and minimum sea ice cover, are presented in Figure 4. Though variability in the monthly SIE values can be seen, all 12 models depicted distinct seasonal and interannual SIE cycles in all three experimental cases (Figures 1-3). The dark gray contour lines in Figures 2 and 3 denote the isoline of $1 \times 10^{6} \mathrm{~km}^{2}$, representing the nearly ice-free Arctic state. The timing of projected nearly ice-free Arctic is examined in more detail in Section 3.4.
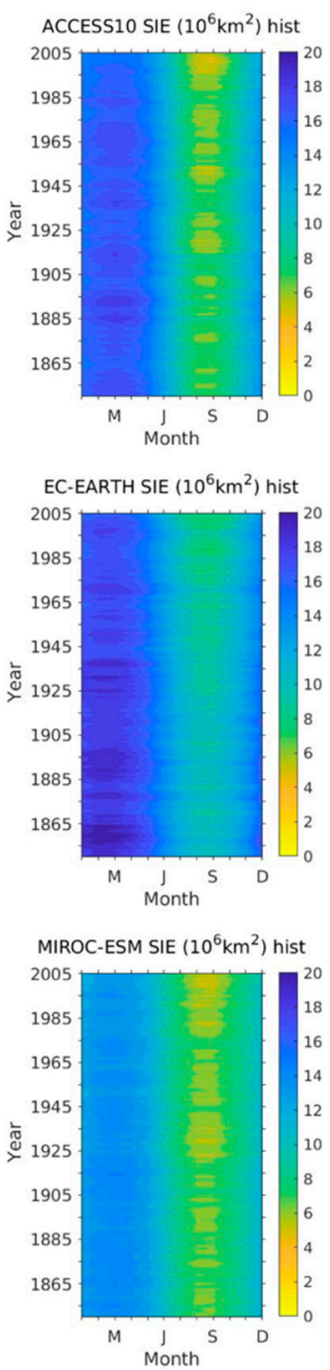
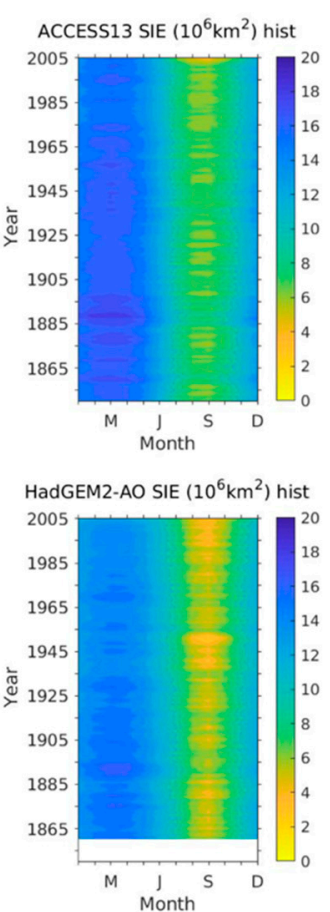

MIROC-ESM-CHEM SIE $\left(10^{6} \mathrm{~km}^{2}\right)$ hist

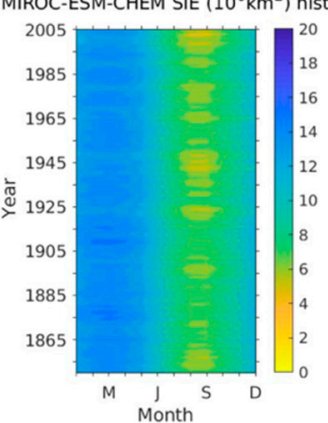

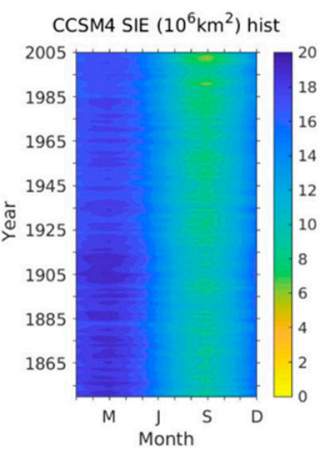
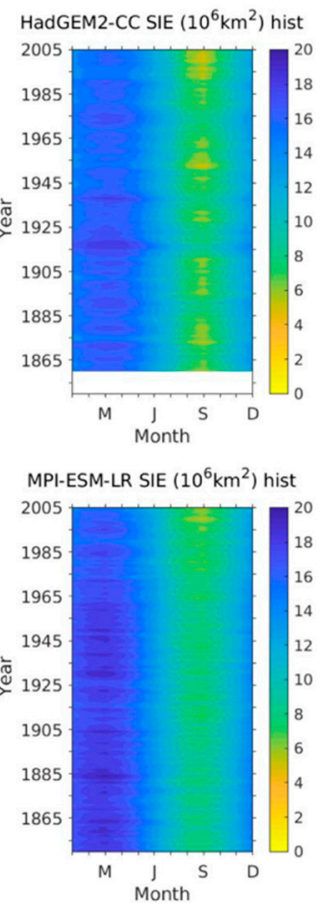
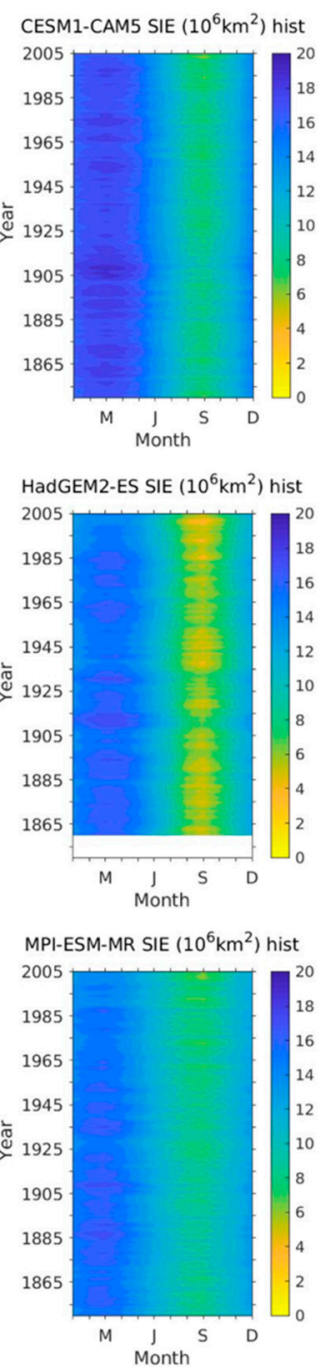

Figure 1. Temporal distributions of simulated historical sea ice extents (SIEs) from 12 Coupled Model Intercomparison Project-Phase 5 (CMIP5) global climate models (see Table 1 for model short names). 

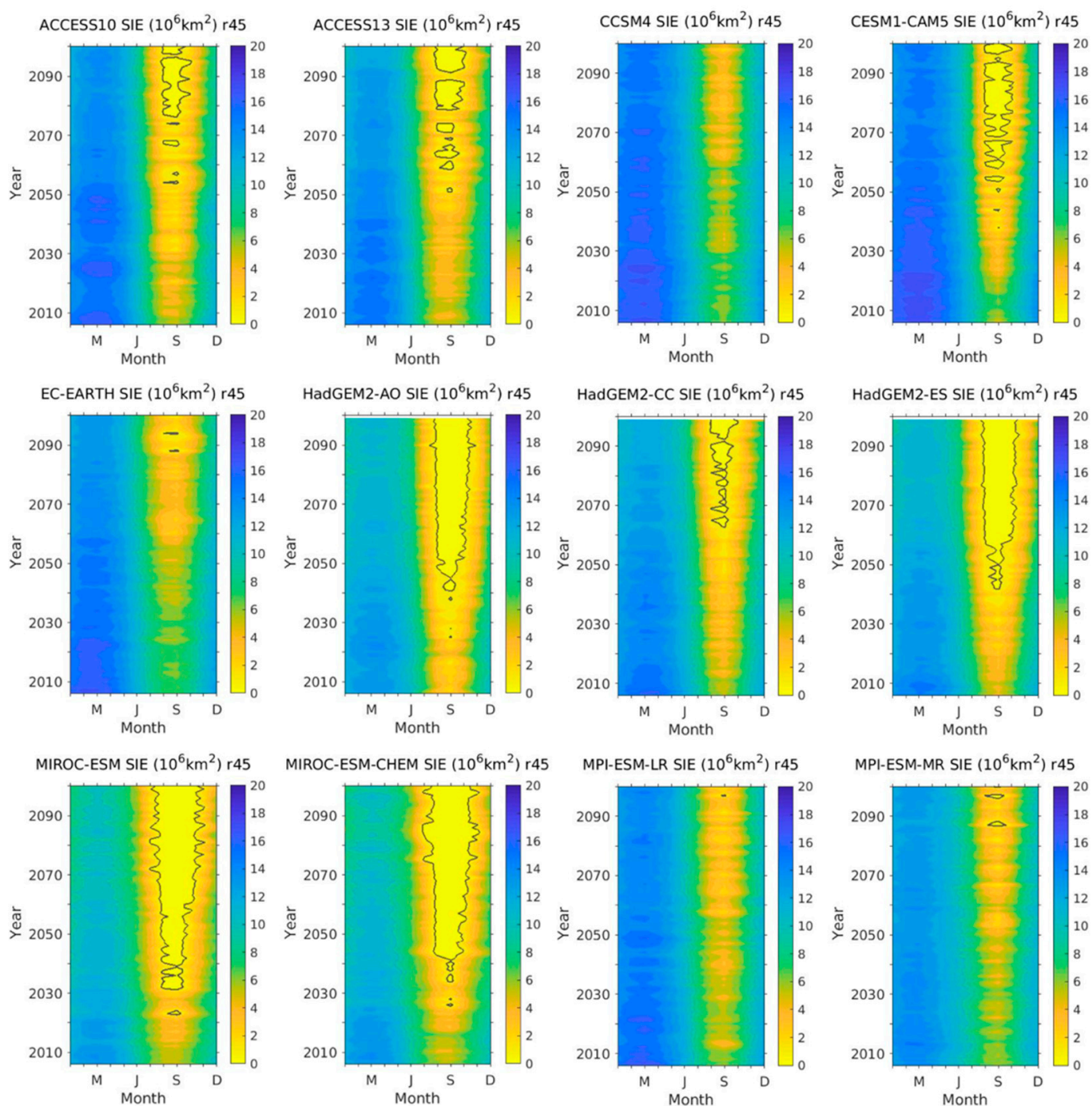

Figure 2. Same as Figure 1 except for a midrange emission scenario Representative Concentration Pathway 4.5 (RCP4.5) (r45). The dark gray contour lines denote the SIE value of one million square kilometers (i.e., $1 \times 10^{6} \mathrm{~km}^{2}$ ). 

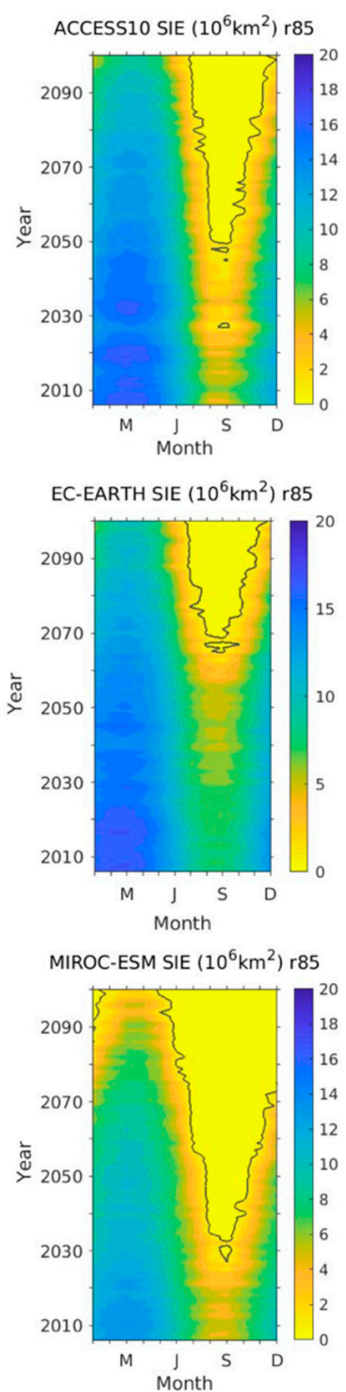

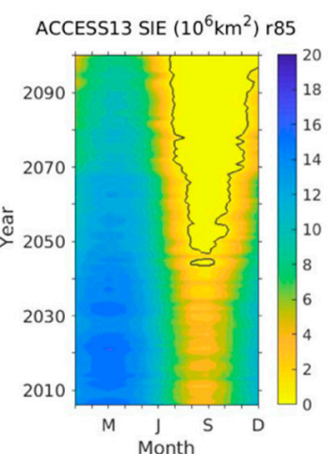

HadGEM2-AO SIE $\left(10^{6} \mathrm{~km}^{2}\right) \mathrm{r} 85$

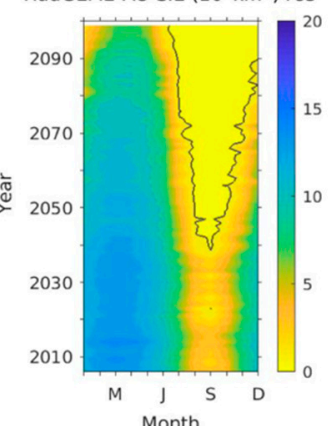

MIROC-ESM-CHEM SIE $\left(10^{6} \mathrm{~km}^{2}\right) \mathrm{r} 85$

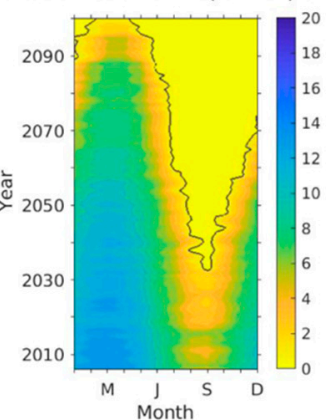

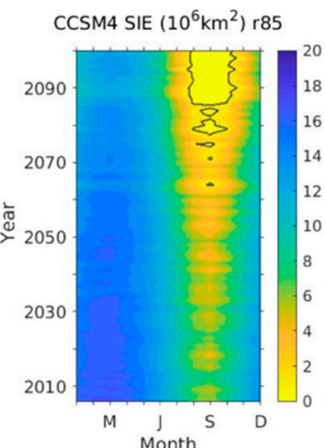

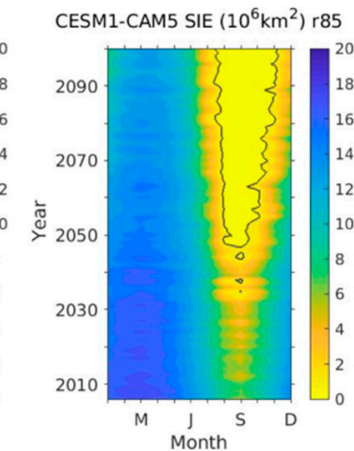

HadGEM2-CC SIE $\left(10^{6} \mathrm{~km}^{2}\right)$ r 85
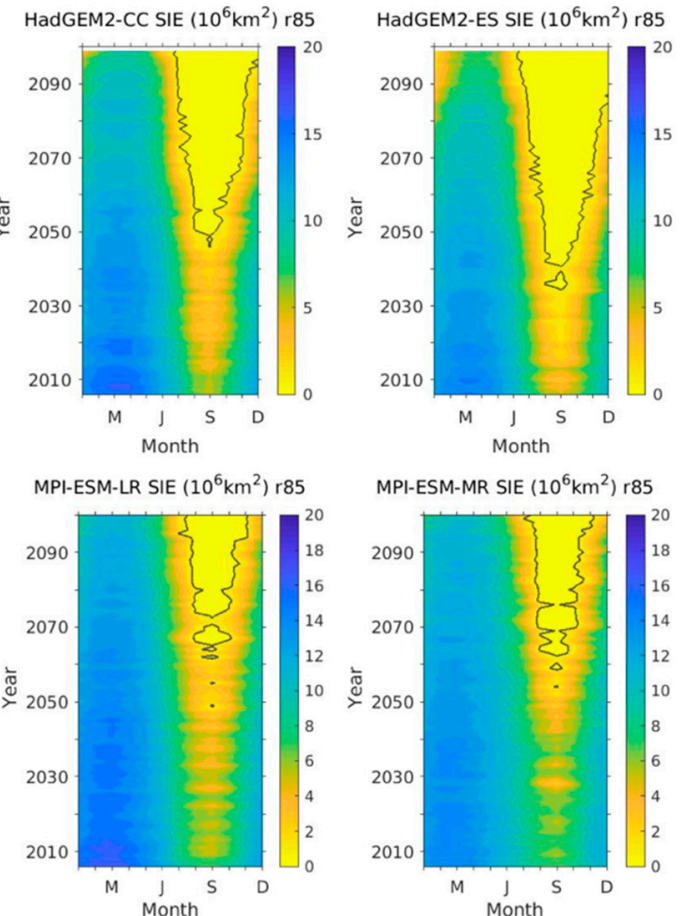

MPI-ESM-MR SIE $\left(10^{6} \mathrm{~km}^{2}\right)$ r85

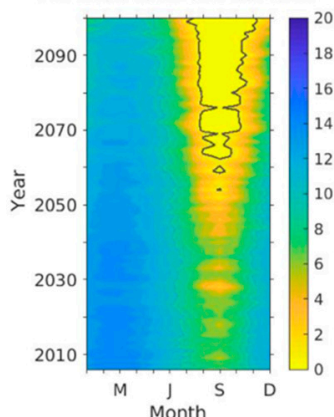

Figure 3. Same as Figure 2 except for the high emission scenario RCP8.5 (r85).
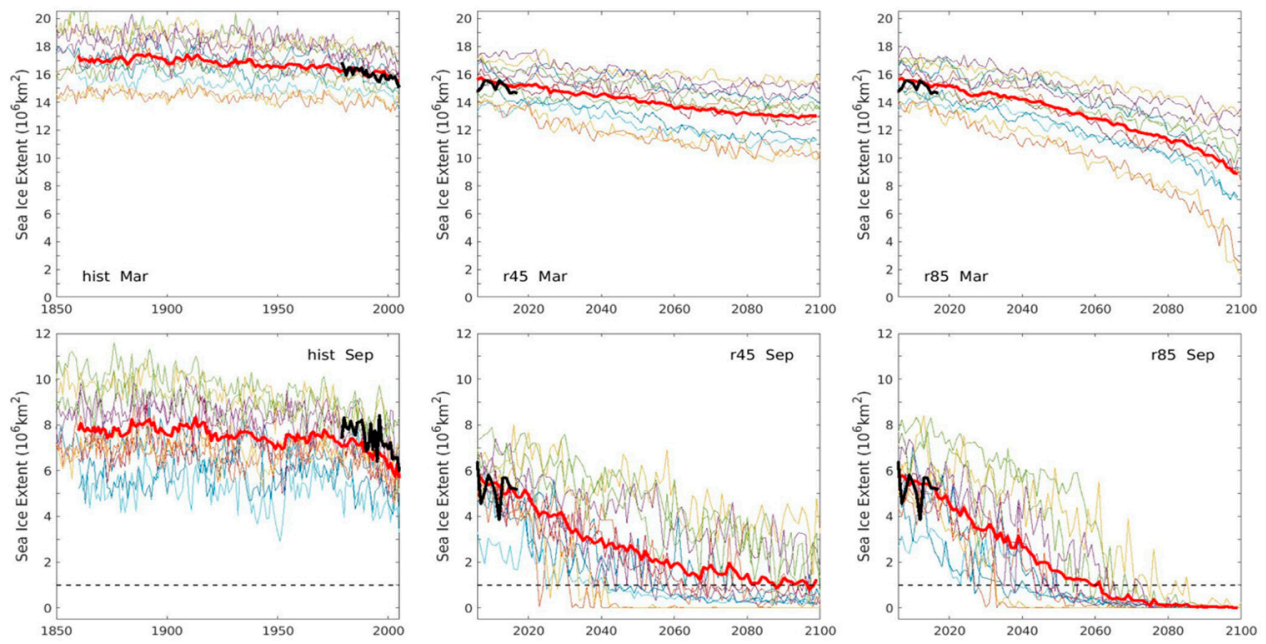

Figure 4. Time series of model sea ice extent (SIE) in March (top panels) and September (lower panels) for historical simulations (hist, left panels), RCP4.5 projections (r45, middle panels), and RCP8.5 projections ( $\mathrm{r} 85$, right panels). The thick red and black solid lines are ensemble means of all model runs and the observations, respectively. The black dashed lines denote the ice-free Arctic threshold of $1 \times$ $10^{6} \mathrm{~km}^{2}$. See Table 1 for the list of 12 climate models and their attributes. 
A noticeable reduction of the mean Arctic SIE maximum, represented by the March Arctic SIE, could be seen based on model projections, with that of 85 being more pronounced near the end of the 21st century (Figure 4). The March Arctic SIE projections for $r 85$ were more spread out at the end of this century, with one model (MICRO-ESM-CHEM) actually projecting the maximum SIE value as approaching the Arctic ice-free threshold at $1.59 \times 10^{6} \mathrm{~km}^{2}$, a value significantly smaller than those projected by other models. Giving the current and foreseeable future Arctic conditions, March SIE values are not likely to be this low. Further analysis needs to be carried out to find out the reason behind this projection. However, this analysis is out of the scope of current study.

The depletion of the Arctic SIE minimum, represented by the September SIE, was captured by the model projections, with a faster rate of SIE decline in the r85 case (Figure 4). All the models projected the Arctic to be ice free by 2065 for the high emission scenario (see Section 3.4 for more details).

While the mean of the Arctic SIE maximums of the hist runs agreed well with the observations, the mean of the Arctic SIE minimums of the hist runs was systematically underestimated compared to the observations (Figure 4).

\subsection{Statistical Characteristics}

It is beneficial to first understand the basic statistical characteristics of SIE time series based on observations, model historical simulations, and projections from different scenarios. For those statistical characteristics to be relevant, we computed them only for periods when the simulations or projections overlapped with observations. The SIE time series based on the Goddard merged sea ice concentrations overlapped with the model simulations over the period of 1979-2005 and with the model projections over the period of 2006-2017. The results are depicted in Tables 2-4.

Table 2. Statistics of SIE time series of historical simulations for 1979-2005. The basic statistics of the model means and observed SIE time series are also included in the last two rows for reference. Units are $10^{6} \mathrm{~km}^{2}$. The bias, root mean square error (RMSE), and mean absolute error (MAE) of the model-simulated SIEs that used the satellite data are listed in the last three columns (they are defined and discussed later in Section 3.3). The values in bold under the Bias, RMSE, and MAE columns denote the maximum magnitudes (not absolute values; superscript a) and the minimum magnitudes (superscript b) amongst all values in the column.

\begin{tabular}{cccccccc}
\hline $\begin{array}{c}\text { Model Short Name. } \\
\text { (Case Type-Hist) }\end{array}$ & Mean & Min & Max & STD & Bias & RMSE & MAE \\
\hline ACCESS10 & 12.1277 & 4.7 & 17.6 & 3.8415 & -0.2878 & 1.1802 & 0.9682 \\
ACCESS13 & 11.7885 & 4.36 & 16.6 & 3.5165 & -0.6269 & 1.1695 & 0.9434 \\
CCSM4 & 13.6377 & 6.25 & 18.7 & 3.4672 & 1.2208 & 1.4853 & 1.2707 \\
CESM1-CAM5 & 13.6405 & 6.41 & 18.4 & 3.3861 & 1.2244 & 1.4697 & 1.2671 \\
EC-EARTH & 13.4292 & 7.45 & 18.5 & 3.4406 & 1.0153 & 1.3501 & 1.1484 \\
HadGEM2-AO & 10.5722 & 3.29 & 15.2 & 3.4767 & -1.8427 & 2.0633 & 1.8474 \\
HadGEM2-CC & 12.2978 & 4.63 & 17.2 & 3.3891 & $-\mathbf{0 . 1 1 6 6} \mathbf{b}^{\mathbf{b}}$ & 0.8826 & 0.7012 \\
HadGEM2-ES & 11.4869 & 4.06 & 16.9 & 3.6571 & -0.9289 & 1.4122 & 1.1515 \\
MIROC-ESM & 10.2487 & 5.24 & 14.6 & 2.8756 & $-\mathbf{2 . 1 6 5 4 ^ { \mathbf { a } }}$ & $\mathbf{2 . 2 6 6 \mathbf { 1 } ^ { \mathbf { a } }}$ & $\mathbf{2 . 1 6 5 4 ^ { \mathbf { a } }}$ \\
MIROC-ESM-CHEM & 10.6744 & 4.45 & 15.1 & 2.8706 & -1.7389 & 1.8838 & 1.7428 \\
MPI-ESM-LR & 12.6344 & 5.58 & 18.3 & 3.5578 & 0.2177 & 0.9427 & 0.7762 \\
MPI-ESM-MR & 11.9817 & 6.46 & 16.4 & 2.5929 & -0.4315 & $\mathbf{0 . 7 6 9 9}$ & $\mathbf{0 . 6 6 1}$ \\
\hline bodel Means & 12.043 & 5.240 & 16.958 & 3.339 & -0.372 & 1.406 & 1.22 \\
OBSERVATIONS & 12.403 & 5.981 & 16.878 & 2.923 & 0 & 0 & 0 \\
\hline
\end{tabular}


Table 3. Statistics of SIE time series of climate model projections for the scenario RCP4.5 (r45) for 2006-2017. The basic statistics of the model means and observed SIE time series are also included in the last two rows for reference. Units are $10^{6} \mathrm{~km}^{2}$. The bias, RMSE, and MAEs of model simulated SIEs that used the satellite data are listed in the last three columns. The values in bold under the Bias, RMSE, and MAE columns denote the maximum magnitudes (not absolute values; superscript a) and the minimum magnitudes (superscript $b$ ) amongst all values in the column.

\begin{tabular}{cccccccc}
\hline $\begin{array}{c}\text { Model Short Name } \\
\text { (Case Type-r45) }\end{array}$ & Mean & Min & Max & STD & Bias & RMSE & MAE \\
\hline ACCESS10 & 11.2194 & 4.40 & 16.9 & 4.0652 & $\mathbf{0 . 0 0 1 9} \mathbf{b}$ & 1.0963 & 0.925 \\
ACCESS13 & 10.8473 & 3.72 & 15.9 & 3.942 & -0.3702 & 1.0917 & 0.8939 \\
CCSM4 & 12.6624 & 6.09 & 17.5 & 3.596 & 1.4450 & 1.5885 & 1.4659 \\
CESM1-CAM5 & 12.9672 & 5.24 & 17.7 & 3.7989 & 1.7498 & 1.9341 & 1.7741 \\
EC-EARTH & 12.2539 & 6.67 & 17.4 & 3.4701 & 1.0364 & 1.2502 & 1.0607 \\
HadGEM2-AO & 9.3219 & 1.66 & 14.0 & 3.8858 & $-\mathbf{1 . 8 9 5 5} \mathbf{a}^{\mathbf{a}}$ & $\mathbf{2 . 1 2 5 7}^{\mathbf{a}}$ & $\mathbf{1 . 8 9 8 0}^{\mathbf{a}}$ \\
HadGEM2-CC & 11.3904 & 3.53 & 16.4 & 3.6622 & 0.1730 & 0.8474 & 0.6553 \\
HadGEM2-ES & 10.6139 & 3.85 & 15.4 & 3.5950 & -0.6036 & 1.0035 & 0.8032 \\
MIROC-ESM & 9.5925 & 3.59 & 14.2 & 3.224 & -1.6249 & 1.8261 & 1.6669 \\
MIROC-ESM-CHEM & 9.9883 & 4.64 & 14.3 & 3.0575 & -1.2292 & 1.4597 & 1.3302 \\
MPI-ESM-LR & 11.6303 & 3.96 & 17.1 & 3.8053 & 0.4129 & 0.9854 & 0.7947 \\
MPI-ESM-MR & 11.1275 & 5.24 & 15.2 & 2.9418 & -0.0899 & $\mathbf{0 . 7 1 7 5}$ & $\mathbf{0 . 5 7 4}$ \\
\hline b & & & & \\
Model Means & 11.135 & 4.383 & 16.000 & 3.587 & -0.083 & 1.327 & 1.153 \\
OBSERVATIONS & 11.217 & 3.857 & 15.554 & 3.290 & 0 & 0 & 0 \\
\hline
\end{tabular}

Table 4. Statistics of SIE time series of climate model projections for the scenario RCP8.5 (r85) for 2006-2017. The basic statistics of the observed SIE time series are also included in the last row in bold for reference. Units are $10^{6} \mathrm{~km}^{2}$. The values in bold under the Bias, RMSE, and MAE columns denote the maximum magnitudes (not absolute values; superscript a) and the minimum magnitudes (superscript b) amongst all values in the column.

\begin{tabular}{cccccccc}
\hline $\begin{array}{c}\text { Model Short Name } \\
\text { (Case Type-r85) }\end{array}$ & Mean & Min & Max & STD & Bias & RMSE & MAE \\
\hline ACCESS1.0 & 11.6199 & 4.38 & 17.0 & 3.9881 & 0.4024 & 1.1024 & 0.9252 \\
ACCESS1.3 & 10.5794 & 3.61 & 16.0 & 4.0235 & -0.6381 & 1.2294 & 1.0295 \\
CCSM4 & 12.7355 & 5.35 & 17.5 & 3.5848 & 1.5180 & 1.6782 & 1.5487 \\
CESM1-CAM5 & 12.9202 & 4.72 & 18.0 & 3.8224 & $\mathbf{1 . 7 0 2 8}^{\mathbf{a}}$ & $\mathbf{1 . 8 8 9 1}^{\mathbf{a}}$ & $\mathbf{1 . 7 3 1 2}^{\mathbf{a}}$ \\
EC-EARTH & 12.7568 & 6.98 & 17.2 & 3.3331 & 1.5394 & 1.6994 & 1.5398 \\
HadGEM2-AO & 9.6455 & 2.37 & 14.7 & 3.8748 & -1.5720 & 1.8671 & 1.5960 \\
HadGEM2-CC & 11.4117 & 3.78 & 16.4 & 3.6287 & 0.1943 & 0.8935 & 0.7128 \\
HadGEM2-ES & 10.2462 & 2.20 & 15.4 & 3.8743 & -0.9712 & 1.3984 & 1.0759 \\
MIROC-ESM & 9.7631 & 4.05 & 14.1 & 3.1855 & -1.4543 & 1.6223 & 1.482 \\
MIROC-ESM-CHEM & 9.8586 & 4.35 & 14.1 & 3.0014 & -1.3588 & 1.5678 & 1.4382 \\
MPI-ESM-LR & 11.7807 & 4.74 & 16.9 & 3.6386 & 0.5632 & 0.9848 & 0.8099 \\
MPI-ESM-MR & 11.2946 & 5.62 & 15.0 & 2.6567 & $\mathbf{0 . 0 7 7 1} \mathbf{b}^{\mathbf{b}}$ & $\mathbf{0 . 8 8 4 8}$ & $\mathbf{0 . 6 7 2 6} \mathbf{b}^{\mathbf{b}}$ \\
\hline Model Means & 11.218 & 4.346 & 16.025 & 3.551 & 0.0 & 1.401 & 1.213 \\
OBSERVATIONS & 11.217 & 3.857 & 15.554 & 3.290 & 0 & 0 & 0 \\
\hline
\end{tabular}

\subsection{Evaluation of Climate Model Simulations and Projections}

The time series of September Arctic SIEs are shown in Figure 5 for hist, r45, and r85. Visually, the ability of these 12 global climate models to simulate and/or project the observed interannual variability varied considerably (Figure 5). The HadGEM2-AO model noticeably and systematically underestimated the September SIEs in all three cases, while HadGEM2-ES and Micro-ESM did so in their historical simulations (Figure $5 \mathrm{a}-\mathrm{c}$ ). On the other hand, the EC-EARTH model tended to systematically overestimate the September SIEs (Figure 5a), and more so for the projections (Figure 5b,c). 
Arctic Sea Ice Extent $\left(10^{6} \mathrm{~km}^{2}\right)$ : hist Sep
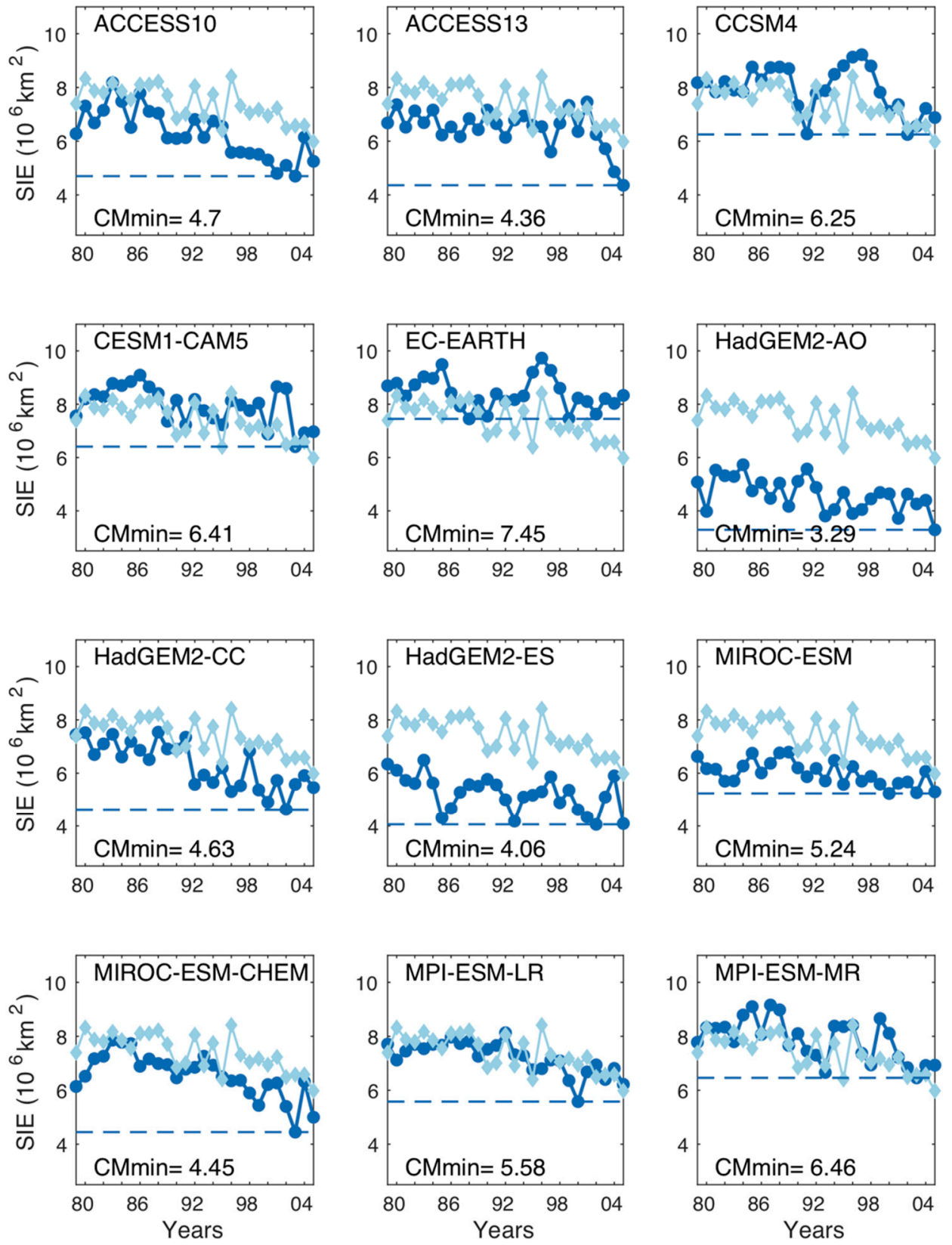

(a)

Figure 5. Cont. 
Arctic Sea Ice Extent $\left(10^{6} \mathrm{~km}^{2}\right): \mathrm{r} 45$ Sep
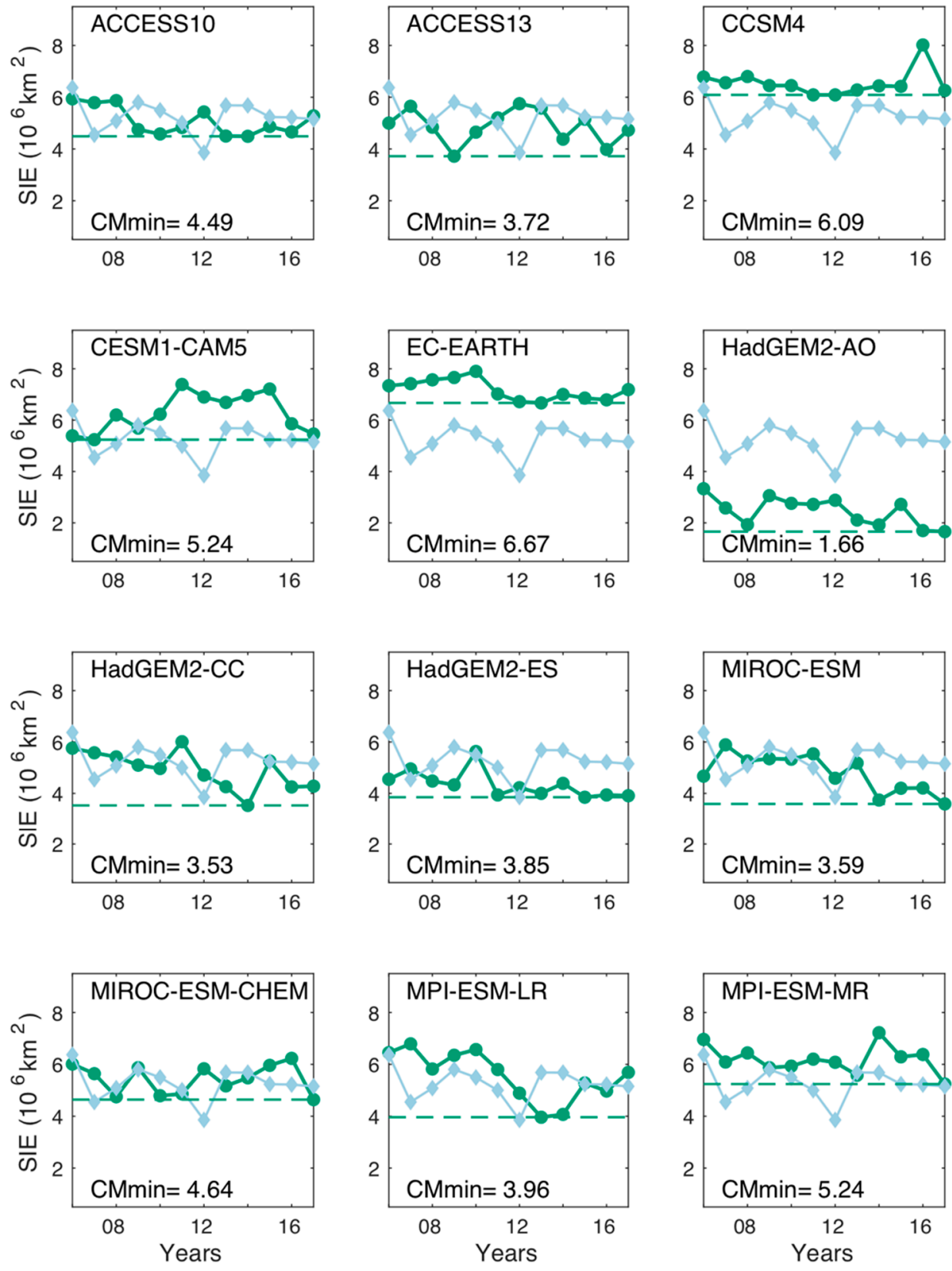

(b)

Figure 5. Cont. 

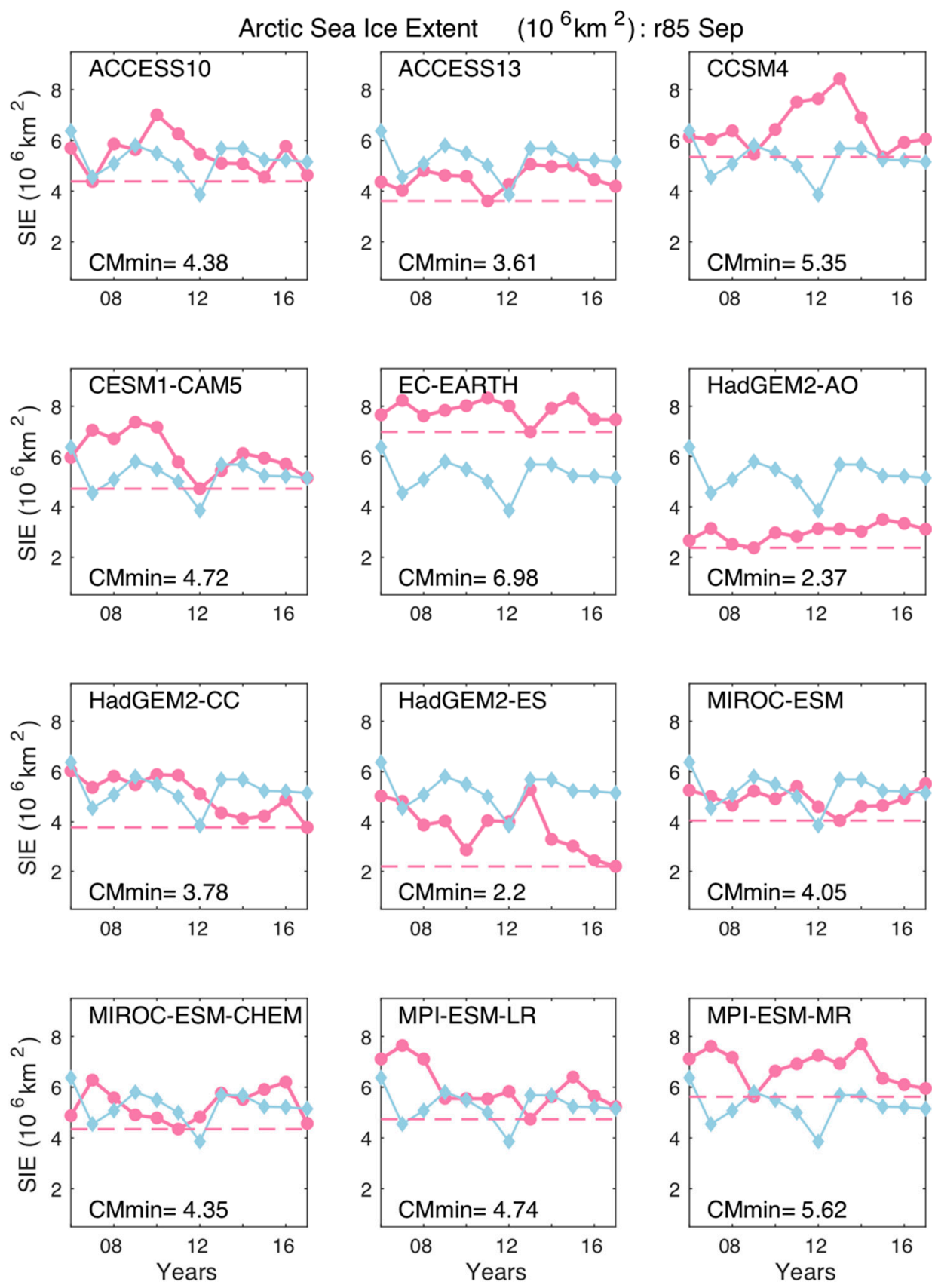

(c)

Figure 5. (a) Time series of simulated Arctic sea ice extents in September by individual climate model (blue solid lines with filled circles) overlaid with the satellite data (light blue solid lines with filled diamonds) for the period of 1979-2005. Dashed lines denote the minimum of the model extent values for the time period, and these values are included in the plots. (b) The same as for Figure 5a except for the projected September Arctic sea ice extents for the RCP4.5 scenario (green) for the period of 2006-2017. (c) The same as in Figure 5b except for the RCP8.5 scenario (pink).

The evaluation of the model simulations and projections (for both the RCP4.5 and RCP8.5 scenarios) was carried out by examining the bias, root mean square error (RMSE), and mean absolute error (MAE) of the model SIEs from the observed SIEs during the overlapping periods.

The model bias was an average of the differences between modeled and observed SIEs that included both positive and negative errors that cancelled each other out. MAE, on the other hand, captures the average of the absolute differences between the modeled and observed SIEs, while the 
RMSE is the square root of the average of squared differences between the modeled and observed SIEs. Though the RMSE is commonly used for measuring model errors, Willmott et al. [26] argued that it may overestimate the average model error, and they recommended using the MAE to help overcome such error overestimation. We therefore decided to include all three statistical metrics in our analysis. Mathematically, they are defined as:

$$
\begin{aligned}
\text { Bias } & =\frac{1}{N} \sum_{j=1}^{N}\left(S I E_{j}-\widehat{S I E}_{j}\right) \\
\mathrm{RMSE} & =\sqrt{\frac{1}{N} \sum_{j=1}^{N}\left(S I E_{j}-\widehat{S I E}_{j}\right)^{2}} \\
\mathrm{MAE} & =\frac{1}{N} \sum_{j=1}^{N}\left|S I E_{j}-\widehat{S I E}_{j}\right|
\end{aligned}
$$

where SIEE denotes the observed SIE time series and $N$ is the total number of records within the overlapping period.

The numerical values of SIE model bias, RMSE, and MAE are depicted in Tables 2-4, respectively. For each parameter, two different types of diagrams are shown for model bias and RSME (Figures 6 and 7). Figures 6a and 7a group the results as a function of the experiment types, namely, hist, r45, and r85. They show the spread of the statistical parameters of all 12 models for each experiment type and allow for comparison among different experiment types. Figures $6 \mathrm{~b}$ and $7 \mathrm{~b}$ group the results as a function of individual models. They show the spread of the statistical parameters across the different experiments for a given model and allow for comparison among models.

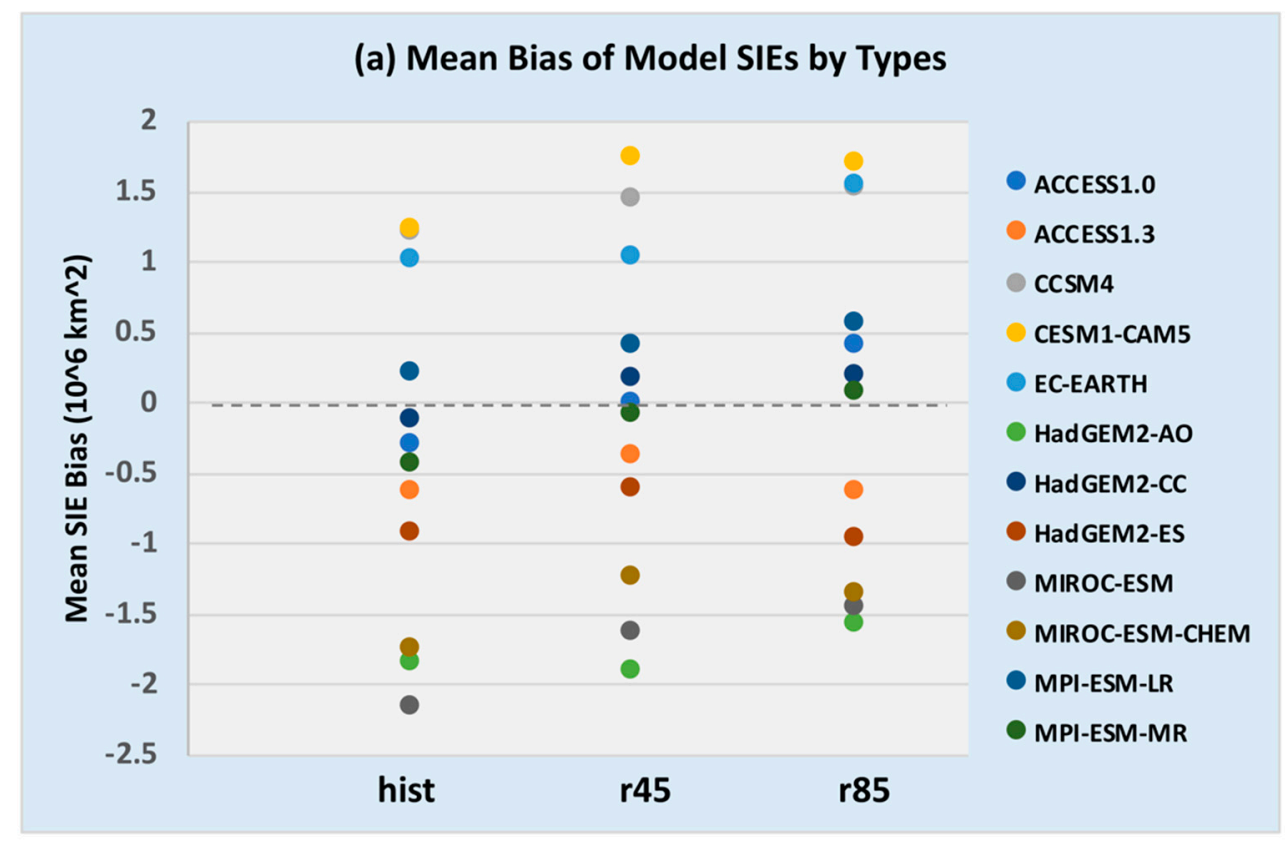

Figure 6. Cont. 


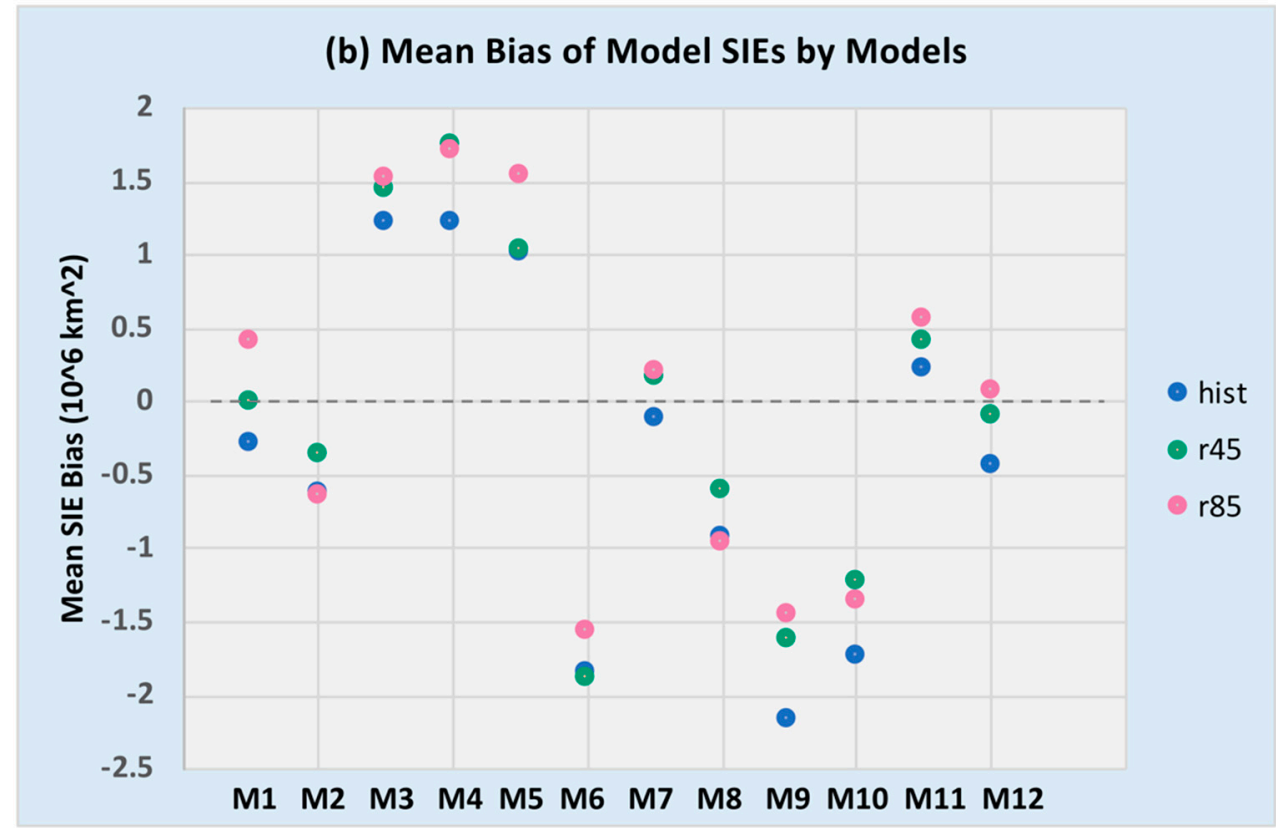

Figure 6. The mean bias of the model SIEs from the observed SIEs as a function of (a) types of runs and (b) models. The record period for the historical simulations (hist) was from January 1979 to December 2005. The record period for the projections (r45 and r85) was from January 2006 to December 2017. See Tables $2-4$ for the numerical values of the mean bias and Table 1 for climate models associated with the model ID in (b).

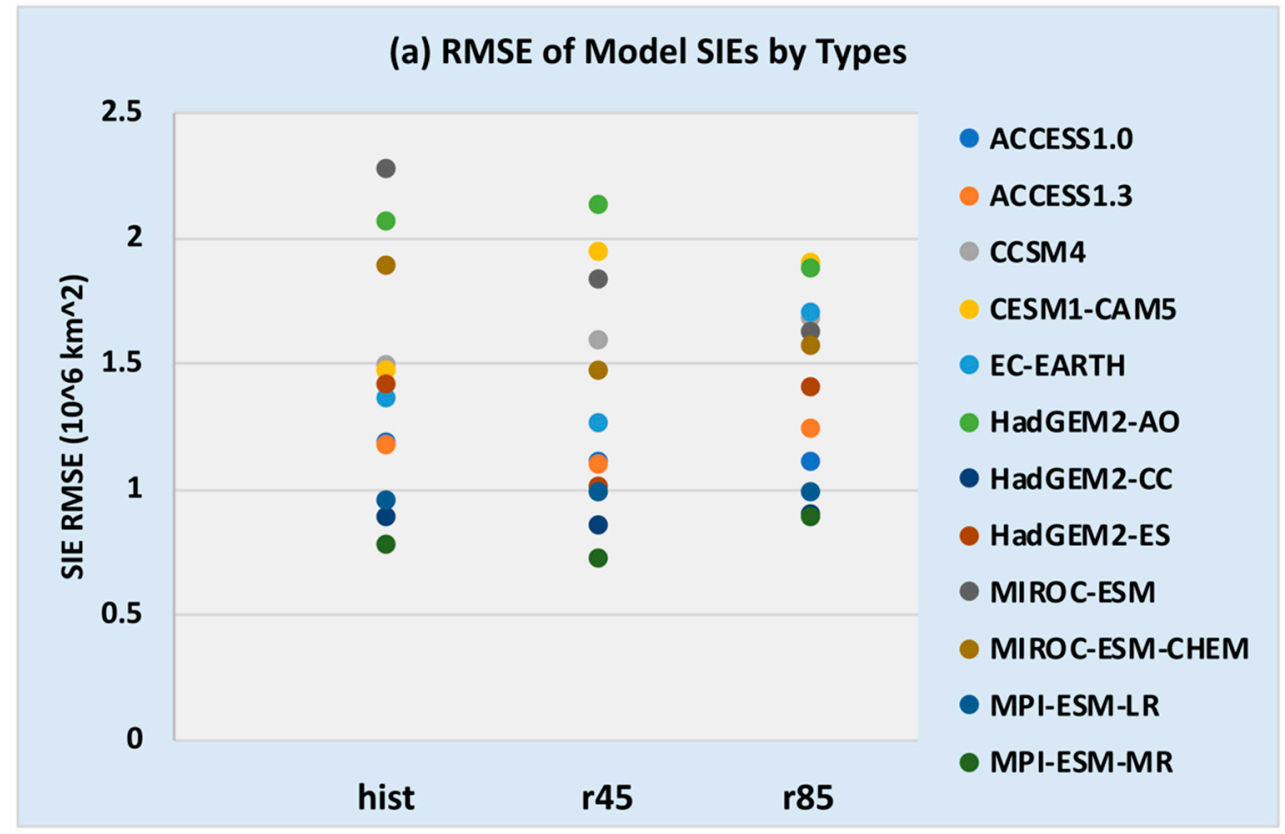

Figure 7. Cont. 


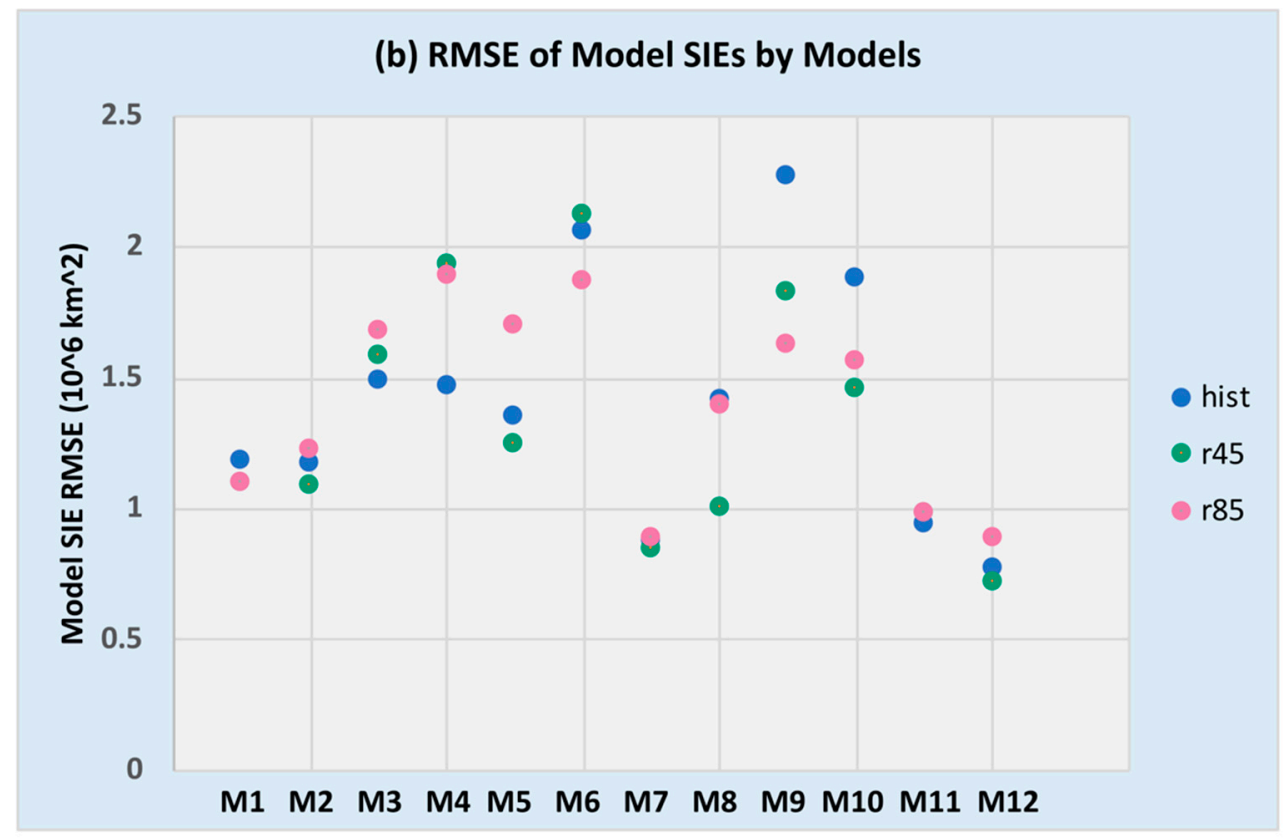

Figure 7. The same as Figure 6 except for the root mean square errors (RMSE) of model SIEs from observed.

For the historical simulations, HadGEM2-CC yielded the smallest bias magnitude at -0.1166 $\left(10^{6} \mathrm{~km}^{2}\right)$. MPI-ESM-LR was the next closest at $0.2177\left(10^{6} \mathrm{~km}^{2}\right)$, while ACCESS10 ranked as third smallest at $0.2878\left(10^{6} \mathrm{~km}^{2}\right)$. At the same time, MIROC-ESM had the largest bias magnitude at -2.1654 $\left(10^{6} \mathrm{~km}^{2}\right)$. Eight out of 12 models had negative bias values, with an average model bias value of -0.372 $\left(10^{6} \mathrm{~km}^{2}\right)$ (Table 2). The bias values of the projections were more evenly spread in both positive and negative domains, with an average value of $-0.083\left(10^{6} \mathrm{~km}^{2}\right)$ for $\mathrm{r} 45$ and zero for r85 (Tables 3 and 4 and Figure 6). There was no obvious systematic change for different experiment types for each model, and HadGEM2-CC appeared to have a smaller bias overall than other climate models (Figure 6b).

MPI-ESM-MR yielded the lowest overall RMSE values for all three cases, with HadGEM2-CC being the second lowest (Tables $2-4$ and Figure 7). MIROC-ESM had the highest RMSE value for the historical simulation case, while HadGEM2-AO and CESM1-CAM5 had the highest RMSEs for the other two projection cases (Figure 7; see also Tables 2-4). The overall spread of all models was smaller in the r85 case (Figure 7a). Similar results were found for the MAE (Tables 2-4; Figure not shown).

\subsection{First Ice-Free Arctic Summer Year (FIASY)}

As discussed earlier, the first occurrence of an ice-free Arctic summer is defined as the first year when the projected summer SIE falls below $1 \times 10^{6} \mathrm{~km}^{2}$. The FIASY values were identified based on the model projected SIE values. The results are summarized in Table 5. 
Table 5. The first ice-free Arctic summer year (FIASY) for the RCP4.5 (r45) and RCP8.5 (r85) scenarios.

\begin{tabular}{llll}
\hline $\begin{array}{l}\text { Models Short Name } \\
\text { /Basic Statistics }\end{array}$ & $\begin{array}{l}\text { FIASY for RCP4.5 } \\
\text { (Case r45; Unit: Year) }\end{array}$ & $\begin{array}{l}\text { FIASY for RCP8.5 } \\
\text { (Case r85; Unit: Year) }\end{array}$ & $\begin{array}{l}\text { RCP8.5-4.5 } \\
\text { (Unit: Year) }\end{array}$ \\
\hline ACCESS10 & 2054 & 2027 & -27 \\
ACCESS13 & 2051 & 2044 & -7 \\
CCSM4 & 2100 & 2064 & $<-36$ \\
CESM1-CAM5 & 2038 & 2035 & -3 \\
EC-EARTH & 2088 & 2065 & -23 \\
HadGEM2-AO & 2025 & 2023 & -2 \\
HadGEM2-CC & 2063 & 2046 & -17 \\
HadGEM2-ES & 2042 & 2035 & -7 \\
MIROC-ESM & 2023 & 2027 & 4 \\
MIROC-ESM-CHEM & 2026 & 2033 & 7 \\
MPI-ESM-LR & 2097 & 2049 & -48 \\
MPI-ESM-MR & 2087 & 2054 & -33 \\
\hline Mean & 2054 & 2042 & -14 \\
Min (Absolute Value) & 2023 & 2023 & 2 \\
Max (Absolute Value) & $>2100$ & 2065 & 48 \\
Spread & $>77$ & 42 & 55 \\
\hline
\end{tabular}

The earliest projected FIASY values for the RCP4.5 scenario were 2023, 2025, and 2026 from the MIROC-ESM, HadGEM2-AO, and MIROC-ESM-CHEM models, respectively. The earliest projected FIASY for RCP8.5 was 2023 for HadGEM2-AO. Except for MIROC-ESM and MIROC-ESM-CHEM, the models tended to project earlier FIASYs for RCP8.5 than that for RCP4.5 (Table 5). As discussed in the Introduction, it is unlikely that the Arctic summer will be nearly ice free (i.e., a SIE is less than $1.0 \times 10^{6} \mathrm{~km}^{2}$ ) by the early 2020s.

The latest FIASY for RCP8.5 was 2065 by EC-EARTH. The CCMS4 model produced the second latest FIASY for RCP8.5, with a value of 2064, and it never reached the ice-free stage by 2100 for RCP4.5. The MPI-ESM-LR and MPI-ESM-MR models tended to produce FIASY values on the high end in the RCP4.5 runs, while they were closer to the mean in the RCP8.5 runs.

Excluding the values later than 2100, the mean FIASY value for RCP4.5 was 2054 with a spread of 74 years; for RCP8.5, the mean FIASY was 2042 with a spread of 42 years (Table 5). The earliest projected FIASY was at year 2023 for both scenarios, but the latest FIASY value was reduced from later than 2100 for RCP4.5 to 2065 for RCP8.5. Therefore, the mean of the projected FIASYs were earlier and the range was tighter for the RCP8.5 compared to the RCP4.5 scenario. Given the fact that the FIASY value from CCSM4 was later than 2100 for the RCP4.5 scenario, the mean FIASY value for the RCP4.5 scenario was later than 2054; the spread was larger than 77.

The sensitivity of individual models to these two different scenarios, however, greatly varied. For example, the absolute difference was 48 years for M11 (MPI-ESM-LR) but about two years for M6 (HadGEM2-AO) (Table 5). Both HadGEM2-AO and MICRO-ESM consistently yielded earlier FIASY values in both scenarios compared to others. When the differences were less than 10 years between the two scenarios, nearly all the projected FIASYs were before 2050, an indication that before mid-century, the choice of scenario was less important for the future Arctic sea ice projections, as stated by Overland et al. [27].

\subsection{Sensitivity of Different Statistical Curve-Fitting Functions}

Peng et al. [4] used six commonly used statistical models to curve-fit satellite observational data in order to examine the nature and sensitivity of Arctic sea ice extent trends. In this section, the same approach is utilized to examine the nature of climate model SIE projections and the sensitivity of the FIASY projections to scenarios and models.

As pointed out in [4], the probability that the statistical curving-fitting model is the best of the sample can be presented by the W-Akaike weights, denoted as the optimized statistical curve-fitting 
model. The W-Akaike weights were computed by using climate model historical simulation and projections for the following four periods and captured in Tables S1 and S2: (i) 1979-2008, (ii) 1979-2017, (iii) 1988-2017, and (vi) 2006-2035. The first three periods corresponded to different subsets of the satellite data record (the first 30 years, the whole period, and the last 30 years, respectively), while the fourth period corresponded to the first 30 years of the climate model projections. The weights were computed for both RCP4.5 and RCP8.5 scenarios.

Figure 8 (top panel) contains all the FIASY values predicted by the six statistical models (denoted by different shapes) that were curve-fitted with the SIEs values for each of the four different periods from each of the 12 climate models and color-coded for the RCP4.5 and 8.5 scenarios. The bottom panel shows the counts of two-year bins from 2010 to 2100 based on all FIASY values within each of the four periods.

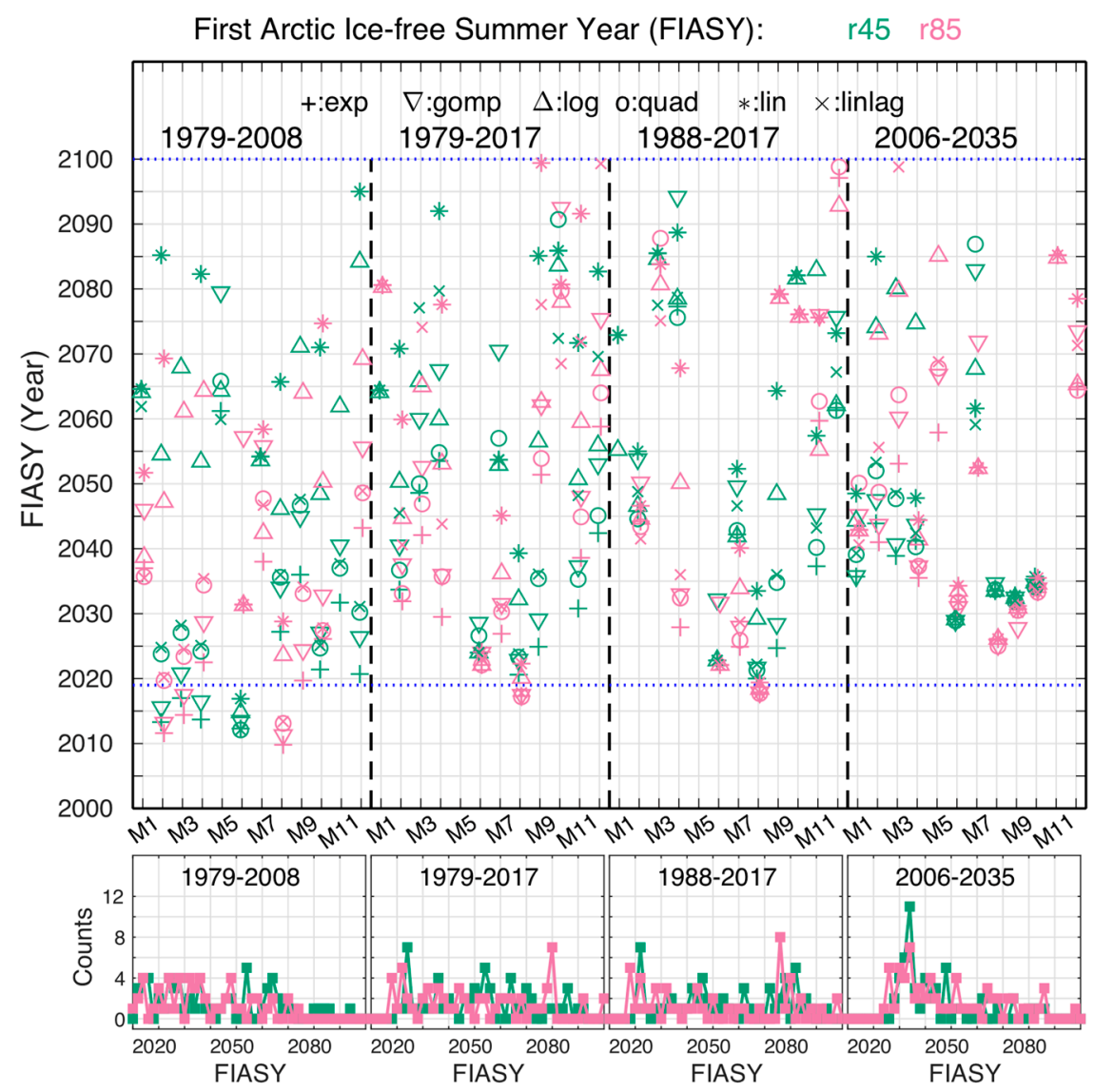

Figure 8. Top panel: the FIASYs predicted by the six curve-fitting models for each of the 12 climate models for the four considered periods, separated by the dashed vertical lines. Horizontal dotted line denotes the current year 2019. Bottom panel: the occurrence of predicted FIASYs from all six statistical models within each two-year bin. FIASY values later than 2100 are not included in the diagram. Green/pink colors indicate the r45/r85 scenarios, respectively. The shapes denote the types of curve-fitting models, as described by the legend of the top panel.

There were no obviously dominant FIASY peaks except for the one in the last period (2006-2035, the first 30 years of model projections). Generally speaking, the distribution of the FIASY values for the first period (1979-2008), which were mostly based on historical simulations, was fairly broad but tended to be slightly earlier, ranging from 2015 to 2065. For the second period (1979-2017), the distribution was fairly broad and evenly distributed from 2020 to 2075, with no obvious coherence between the RCP4.5 and RCP8.5 scenarios. The coherence between the two scenarios was slightly improved for the third period (1988-2017). For this case, there were two preferred time frames for predicted FIASY values: One was around year 2020, and the other was around year 2080. This is very 
different from the results found by Peng et al. (2018), where the predicted FIASY values converged to 2037. Again, since the most recent observed annual Arctic sea ice minimum was at $4.15\left(10^{6} \mathrm{~km}^{2}\right) \mathrm{on}$ 18 September 2019, the prospect of an ice-free Arctic summer in or around 2020 is not realistic.

A more distinct peak at 2034 for both scenarios could be seen in the last considered period (2006-2035); the overall distributions of FIASYs for both scenarios were also more consistent than those of the other three periods.

For all the considered cases, the model SIE simulations and projections were shown to be unlikely to be logarithmic in nature, while the likelihood of being either linear or quadratic was fairly close for the first two periods (Figure 9; see also Tables S1 and S2). The Gompertz statistical model tended to predict earlier FIASYs than is realistic (earlier than 2019 for these two periods); the same can be said for the exponential statistical model for the first period, which gave FIASY values at or earlier than 2019 (Figure 9; see also Tables S3a,b and S4a,b). The linear curve-fitting model seemed to be the preferable choice, more so for the last two periods for the r45 scenario (Figure 9; see also Table S1c,d). The preference for being linear was slightly weaker for all four periods in the r85 scenario, where the increase was more quadratic (Figure 9; see also Table S2c,d).

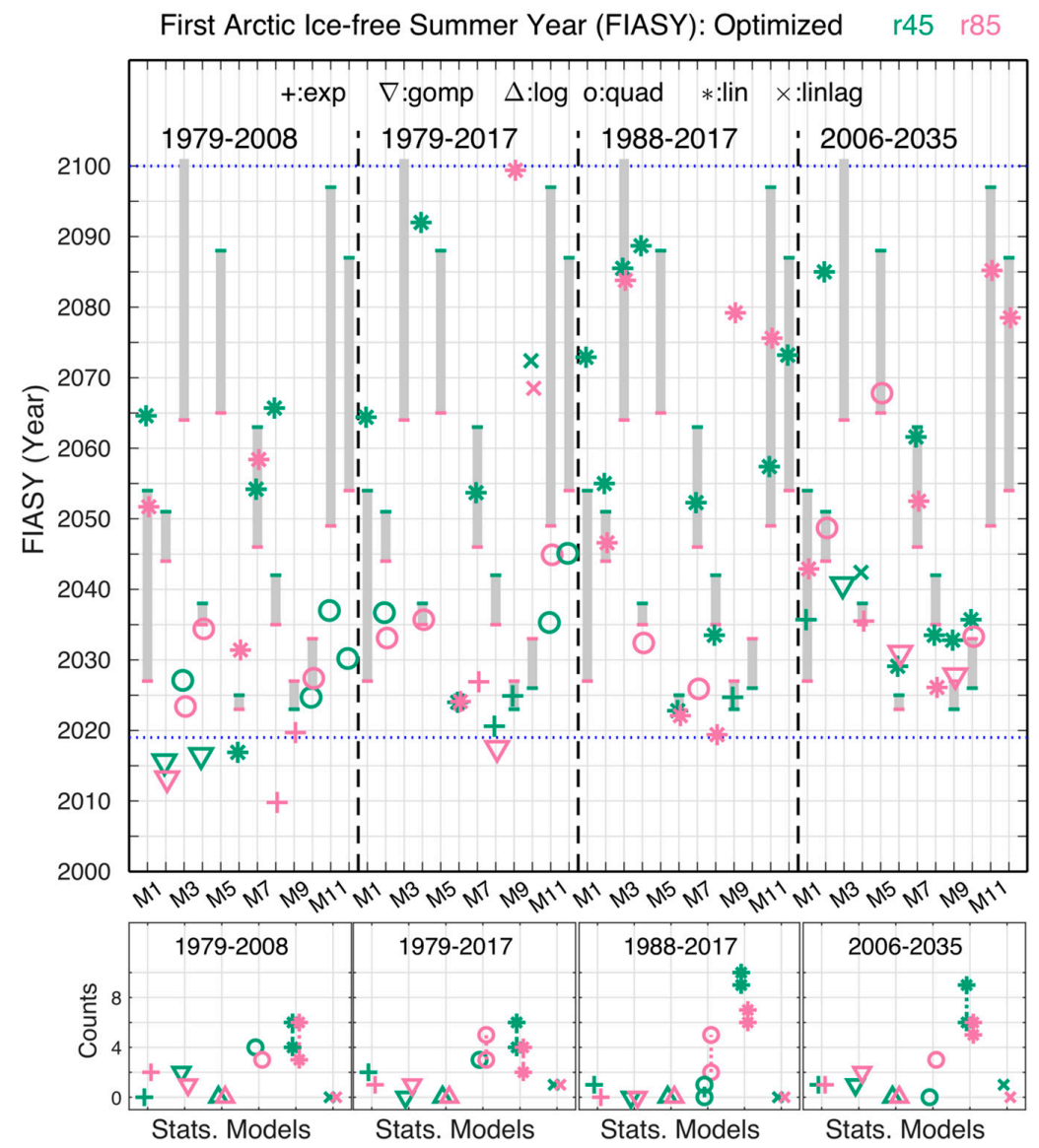

Figure 9. Top panel: the predicted FIASY by the optimal curve-fitting model for each of the 12 climate models for the four considered periods. Green/pink colors are for the r45/r85 scenarios, respectively. The grey vertical bars in each period represent the spread of the FIASY values from the r45/r85 projections (see Section 3.4). Bottom panel: the count of how many times each of the six statistical curve-fitting models was selected as the optimal model for each of the four periods when using FIASY values lower than 2100. FIASY values later than 2100 are represented in the diagram by adding the value to that of the same statistical model. The shapes denote the types of the curve-fitting models, as described by the top panel legend. 
By using the range of the FIASY values estimated from the projections shown in the previous subsection (shaded bars in the top panel of Figure 9), we could assess the feasibility of the FIASY values predicted by the optimal statistical models. For the first 30 years of the climate model projections (2006-2035), the FIASY values predicted by the optimal statistical model fell within the range of projected ranges for nine out of 11 climate models in the RCP8.5 scenario (one with the FIASY value later than year 2100); however, this only occurred for two climate models in the RCP 4.5 scenario (Figure 9, top panel). In contrast, six out of 10 models fell within the projected ranges in the RCP4.5 scenario for the last 30 years of the satellite data (1988-2017), but only four out of eight did so in the RCP8.5 scenario. With just two climate models from either scenario falling within projected ranges, the whole satellite record period of 1979-2017 turned out to have the least predictive skill for all six statistical models. For the first 30 year period (1979-2008) of satellite observations, four models fell in projected ranges for the RCP8.5 scenario, but only one did so for the RCP4.5 scenario.

\section{Discussion}

By utilizing all ensemble members with CESM1-CAM5, Jahn et al [28] showed that the sensitivity of CESM1-CAM5 to the different scenarios in terms of projecting FIASY values is about five years. Our results when using just one ensemble member of CESM1-CAM5 showed a difference of about three years. However, our results also showed that the sensitivity to the different scenarios of projecting FIASYs when using the 12 climate models was quite different, ranging from two to 48 years with a mean of 14 years. This could imply that the results from any impact study of depleting Arctic sea ice when using an individual climate model may be limited to that model system, and one should be cautious when trying to generalize. The similar conclusion was reached by the authors of [27] in the context of selecting global climate models for regional climate projections. Overland et al. [27] stated: "The use of a single model is not recommended."

On the other hand, the limitation of our analysis lies with the fact that we only used outputs from one ensemble member with each of the 12 climate models. There were three ensemble members from CESM1-CAM5. The time series of the September Arctic SIE projected from the CESM1-CAM5 ensemble member used in this analysis is shown in Figure 10a (thick solid lines) for both the RCP4.5 (green) and RCP8.5 (pink) scenarios. Two other members are plotted in thin solid lines. The same was done for MPI-ESM-LR, which had the largest difference in FIASYs for the different scenarios (Figure 10b). This figure is presented to show the consistency and uncertainty of different ensemble members for two different climate models for different scenarios. For example, the projected FIASY value from a different $\mathrm{r} 45$ ensemble member of MPI-ESM-LR resulted in a much earlier FIASY value that reduced the spread between two scenarios (Figure 10b). It was, however, beyond the scope of this study to investigate whether the existing ensemble numbers of all CMIP5 global climate models are sufficient for capturing the full spectrum of the Arctic sea ice state. 
(a) CESM1-CAM5 Arctic September

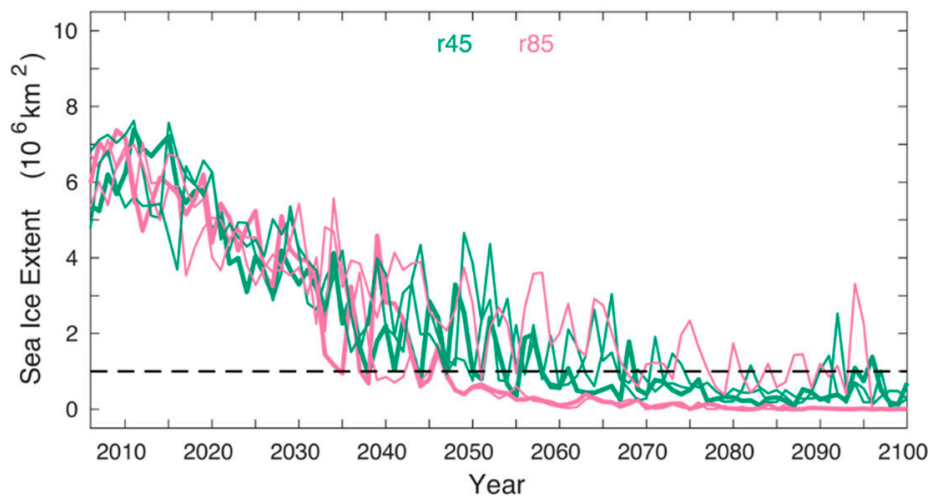

(b) MPI-ESM-LR Arctic September

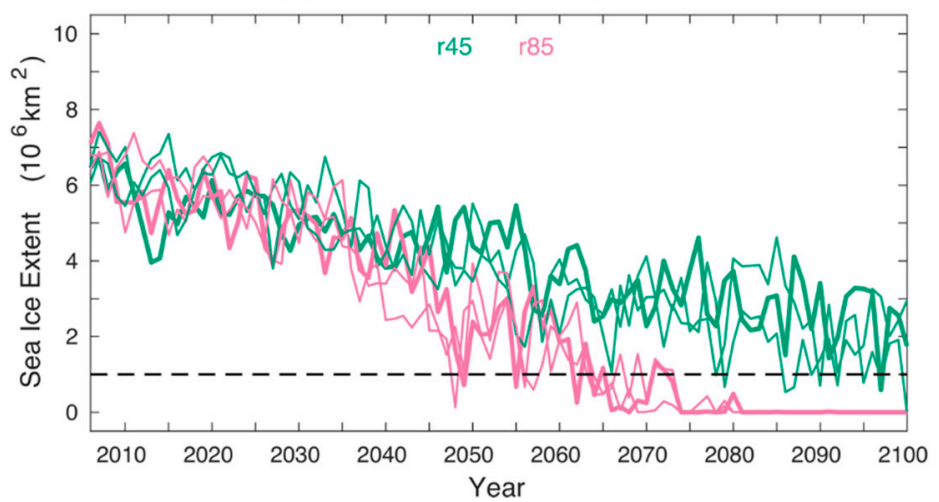

Figure 10. Time series of Arctic sea ice extents $\left(10^{6} \mathrm{~km}^{2}\right)$ in September of three ensemble members from (a) CESM1-CAM5 and (b) MPI-ESM-LR, color-coded for the RCP4.5 (r45 in green) and RCP8.5 (r85 in pink) scenarios. The thick solid lines denote the time series used in our analysis.

\section{Summary}

Monthly Arctic sea ice extent from historical simulations and projections for the RCP4.5 and RCP8.5 scenarios based on 12 CMIP5 climate models were utilized to examine the performance and the nature of modeled Arctic sea ice coverage changes. These 12 CMIP5 climate models were selected based on their ability to reasonably simulate the seasonal Arctic sea ice cycle, with the goal of minimizing the uncertainty of their sea ice projections and our analysis. The presented analysis was not only on all 12 models as a whole but also on each of these individual models. This will be useful for the modeling group and end-users.

The performances of the global climate models in terms of simulations and projections were examined by using the satellite-based sea ice climate data record. HadGEM2-CC yielded the smallest bias compared to others, while MPI-ESM-MR produced the smallest RMSE and MAE values, with HadGEM2-CC giving the second-smallest RMSE and MAE values.

For individual models, generally speaking, the models with smaller biases for the historical simulation runs did not necessarily yield smaller biases for their projection runs. The SIEs from the higher emission scenario runs were not necessarily closer to the observations.

Excluding the values later than 2100, the averaged projected FIASY value for RCP4.5 was 2054 with a spread of 74 years; for RCP8.5, the averaged FIASY was 2042 with a spread of 42 years. Both FIASY values were later than those from previous studies, e.g., [1,4], which put the mean FIASY at 2037. The RCP8.5 projections tended to push FIASY earlier, except for those of the MICRO-ESM and MICRO-ESM-CHEM models. Those two models also tended to project earlier Arctic ice-free dates and longer durations, as denoted by the wider ice-free threshold lines in Figure 3. 
Overall, the change in Arctic sea ice extents projected by climate models appears to be mostly linear, with the quadratic model being secondary in nature. The linear statistical model was found to be the dominant optimized curve-fitting model for both the last 30 years (1988-2017) and the first 30 years of the climate projections (2006-2035), particularly for the RCP4.5 scenario. The frequency distributions of the FIASY values that were predicted by the six commonly used statistical models for a 30-year period did not show a distinct peak except for those that were curve-fitted with the first 30 years of climate projections (2006-2035). In that case, the distributions showed a preferred range of 2030-2040, with a distinct peak at 2034 for both scenarios, which is more comparable with those from previous studies.

Based on the conclusion that linear regression models generally provide the best fit to the climate model projections and the fact that observed SIEs are decreasing faster than the resulted linear regressions are predicting, climate models may be collectively underestimating the rate of change in SIE. The mean of projected FIASYs may therefore be later than what is actually likely to occur. In addition, the ability of these 12 global climate models to accurately simulate and project the observed interannual variability greatly varies with individual models. Therefore, one can argue that there is still room for improvement for the sea ice sub-models within the global climate model systems.

Supplementary Materials: The following are available online at http://www.mdpi.com/2225-1154/8/1/15/s1.

Author Contributions: R.V. conceptualized and formulated the scientific questions that are the basis of this research. Together with R.V. and J.L.M., G.P. designed the analysis. M.W. computed the monthly Arctic sea ice extent (SIE) time series based on the sea ice concentrations from all 12 CMIP5 climate models for the three experiment types, namely the historical simulations, the RCP4.5 and RCP8.5 scenario runs. G.P. computed the monthly satellite SIE time series and prepared the climate model SIE time series for analysis. J.L.M. carried out the statistical curve-fitting analysis and generated Tables S1-S4. Peng generated the rest of tables, all figures, and drafted the manuscript. J.L.M. contributed to Section 3.5. L.S. contributed to Table 1 and Section 2.1. M.W. contributed to Introduction and Section 3.1. Input from L.S. and M.W. on climate models was beneficial. All authors have reviewed the draft with beneficial edits and approved the submission. All authors have read and agreed to the published version of the manuscript.

Funding: This research received no external funding.

Acknowledgments: Ge Peng, Jessica L. Matthews, and Liqiang Sun were supported by NOAA's National Centers for Environmental Information (NCEI) through the Cooperative Institute for Climate and Satellites-North Carolina (CICS-NC) under Cooperative Agreement NA14NES432003 and the Cooperative Institute for Satellite Earth System Studies (CISESS) under Cooperative Agreement NA19NES4320002. Muyin Wang was jointly supported by the Arctic Research Project of the NOAA Climate Program Office, and by the Joint Institute for the Study of the Atmosphere and Ocean (JISAO) under NOAA Cooperative Agreement NA15OAR4320063, Contribution No 2019-1037. This is Pacific Marine Environmental Laboratory contribution \# 5043. We thank Tom Maycock, Carrie Morrill, and three anonymous reviewers of the MDPI Climate journal for reviewing the manuscript and providing beneficial suggestions that have increased its clarity and readability and helped to improve the quality of the paper. Suggestions from Tom Maycock and Laura Stevens were beneficial in selecting the color-blind-friendly palette used in Figures 1-3. We acknowledge the World Climate Research Programme's Working Group on Coupled Modelling, which is responsible for CMIP, and we thank the climate modeling groups (listed in Table 1 of this paper) for producing and making available their model output. For CMIP, the U.S. Department of Energy's Program for Climate Model Diagnosis and Intercomparison provides coordinating support and led the development of software infrastructure in partnership with the Global Organization for Earth System Science Portals.

Conflicts of Interest: The authors declare no conflict of interest. The funders had no role in the design of the study; in the collection, analyses, or interpretation of data; in the writing of the manuscript, or in the decision to publish the results.

\section{References}

1. Wang, M.; Overland, J.E. A sea ice free summer Arctic within 30 years? Geophys. Res. Lett. $2009,36$. [CrossRef]

2. Wang, M.; Overland, J.E. A sea ice free summer Arctic within 30 years: An update from CMIP5 models. Geophys. Res. Lett. 2012, 39. [CrossRef]

3. Stroeve, J.C.; Kattsov, V.; Barrett, A.; Serreze, M.; Pavlova, T.; Holland, M.; Meier, W.N. Trends in Arctic sea ice extent from CMIP5, CMIP3 and observations. Geophys. Res. Lett. 2012, 39. [CrossRef] 
4. Peng, G.; Matthews, J.L.; Yu, J.T. Sensitivity analysis of Arctic sea ice extent trends and statistical projections using satellite data. Remote Sens. 2018, 10, 230. [CrossRef]

5. ACIA. Impacts of a Warming Arctic-Arctic Climate Impact Assessment; ACIA Overview Report; Cambridge University Press: Cambridge, UK, 2004; p. 140.

6. AMAP. Snow, Water, Ice and Permafrost in the Arctic (SWIPA) 2017; AMAP: Oslo, Norway, 2017; p. 288.

7. IPCC. IPCC Special Report on the Ocean and Cryosphere in a Changing Climate; IPCC: Geneva, Switzerland, 2019.

8. Wang, L.; Derksen, C.; Brown, R.; Markus, T. Recent changes in pan-Arctic melt onset from satellite passive microwave measurements. Geophys. Res. Lett. 2013, 40, 522-528. [CrossRef]

9. NSIDC. Arctic Sea Ice at Minimum Extent for 2019. Available online: https://nsidc.org/news/newsroom/ arctic-sea-ice-minimum-extent-2019 (accessed on 10 April 2019).

10. Wang, M.; Overland, J.E. Projected future duration of the sea-ice-free season in the Alaskan Arctic. Prog. Oceanogr. 2015, 136. [CrossRef]

11. Taylor, K.E.; Stouffer, R.J.; Meehl, G.A. An overview of CMIP5 and the experiment design. Bull. Am. Meteorol. Sci. 2012, 485-497. [CrossRef]

12. Hunke, E.C.; Lipscomb, W.H. CICE: The Los Alamos Sea Ice Model Documentation and Software User's Manual, Version 4.1; Tech. Rep. LA-CC-06-012; Los Alamos National Laboratory: Los Alamos, NM, USA, 2010; p. 76.

13. Bi, D.; Dix, M.; Marsland, S.J.; O’Farrell, S.; Rashid, H.A.; Uotila, P.; Hirst, A.C.; Golebiewski, E.K.M.; Sullivan, A.; Yan, H.; et al. The ACCESS coupled model: Description, control climate and evaluation. Aust. Meteorol. Ocean. J. 2013, 63, 41-64. [CrossRef]

14. Collier, M.; Uhe, P. CMIP5 Datasets from the ACCESS1.0 and ACCESS1.3 Coupled Climate Models; CAWCR Technical Report No. 059; The Centre for Australian Weather and Climate Research: Melbourne, VIC, Australia, December 2012; p. 32.

15. Gent, P.R.; Danabasoglu, G.; Donner, L.J.; Holland, M.M.; Hunke, E.C.; Jayne, S.R.; Lawrence, D.M.; Neale, R.B.; Rasch, P.J.; Vertenstein, M.; et al. The Community Climate System Model version 4. J. Clim. 2011, 24, 4973-4991. [CrossRef]

16. Neale, R.B.; Chen, C.-C.; Gettelman, A.; Lauritzen, P.H.; Park, S.; Williamson, D.L.; Conley, A.; Garcia, R.; Kinnison, D.; Lamarque, J.-F.; et al. Description of the NCAR Community Atmosphere Model (CAM5.0); NCAR Tech. Rep. NCAR/TN-4861STR; The National Center for Atmospheric Research: Boulder, CO, USA, 2012; p. 268.

17. Hazeleger, W.; Wang, X.; Severijns, C.; Ştefănescu, S.; Bintanja, R.; Sterl, A.; Wyser, K.; Semmler, T.; Yang, S.; Van Den Hurk, B.; et al. EC-Earth V2.2: Description and validation of a new seamless earth system prediction model. Clim. Dyn. 2012, 39, 2611-2629. [CrossRef]

18. Collins, W.J.; Bellouin, N.; Doutriaux-Boucher, M.; Gedney, N.; Halloran, P.; Hinton, T.; Hughes, J.; Jones, C.D.; Joshi, M.; Liddicoat, S.; et al. Development and evaluation of an Earth-system model HadGEM2. Geosci. Model Dev. 2011, 4, 997-1062. [CrossRef]

19. Watanabe, S.; Hajima, T.; Sudo, K.; Nagashima, T.; Takemura, T.; Okajima, H.; Nozawa, T.; Kawase, H.; Abe, M.; Yokohata, T.; et al. MIROC-ESM 2010: Model description and basic results of CMIP5-20c3m experiments. Geosci. Model Dev. 2011, 4, 845-872. [CrossRef]

20. Giorgetta, M.A.; Jungclaus, J.; Reick, C.H.; Legutke, S.; Bader, J.; Böttinger, M.; Brovkin, V.; Crueger, T.; Esch, M.; Fieg, K.; et al. Climate and carbon cycle changes from 1850 to 2100 in MPI-ESM simulations for the Coupled Model Intercomparison Project phase 5. J. Adv. Model. Earth Syst. 2013, 5, 572-597. [CrossRef]

21. Meier, W.N.; Fetterer, F.; Savoie, M.; Mallory, S.; Duerr, R.; Stroeve, J. NOAA/NSIDC Climate Data Record of Passive Microwave Sea Ice Concentration, Version 3; National Snow and Ice Data Center: Boulder, CO, USA, 2017. [CrossRef]

22. Cavalieri, D.J.; Parkinson, C.L.; Gloersen, P.; Zwally, H.J. Sea Ice Concentrations from Nimbus-7 SMMR and DMSP SSM/I-SSMIS Passive Microwave Data, Version 1; NASA National Snow and Ice Data Center Distributed Active Archive Center: Boulder, CO, USA, 1996. [CrossRef]

23. Comiso, J.J. Large decadal decline of the Arctic multiyear ice cover. J. Clim. 2012, 25, 1176-1193. [CrossRef]

24. Peng, G.; Meier, W.N.; Scott, D.J.; Savoie, M. A long-term and reproducible passive microwave sea ice concentration data record for climate studies and monitoring. Earth Syst. Sci. Data 2013, 5, 311-318. [CrossRef]

25. Meier, W.N.; Peng, G.; Scott, D.J.; Savoie, M.H. Verification of a new NOAA/NSIDC passive microwave sea-ice concentration climate record. Polar Res. 2014, 33. [CrossRef] 
26. Willmott, C.J.; Robeson, S.M.; Matsuura, K.; Ficklin, D.L. Assessment of three dimensionless measures of model performance. Environ. Model. Softw. 2015, 73, 167-174. [CrossRef]

27. Overland, J.E.; Wang, M.; Bond, N.A.; Walsh, J.E.; Kattsov, V.M.; Chapman, W.L. Considerations in the selection of global climate models for regional climate projections: The Arctic as a case study. J. Clim. 2011, 24, 1583-1597. [CrossRef]

28. Jahn, A.; Kay, J.E.; Holland, M.M.; Hall, D.M. How predictable is the timing of a summer ice-free Arctic? Geophys. Res. Lett. 2016, 43, 9113-9120. [CrossRef]

(C) 2020 by the authors. Licensee MDPI, Basel, Switzerland. This article is an open access article distributed under the terms and conditions of the Creative Commons Attribution (CC BY) license (http://creativecommons.org/licenses/by/4.0/). 